\title{
The relationship between the air content in the mortar and concrete for different types of cement
}

\author{
Beata Laźniewska-Piekarczyk ${ }^{1}$, Jacek Gołaszewski ${ }^{1}$ \\ ${ }^{1}$ Silesian Technical University, Faculty of Civil Engineering, Department of Building Materials \\ and Processes Engineering, Akademicka 5 Str., 44-100 Gliwice, Poland
}

Corresponding author: beata.lazniewska@polsl.pl

\begin{abstract}
Research results of the relationships between air-volume in air-entrained cement paste, mortar and concrete, all designed according to PN-EN 480-1 guidelines are presented in the paper. The cement paste, mortar and concrete, with $\mathrm{w} / \mathrm{c}=0,5$ ratio, were prepared using innovative air-entraining cement CEM II/B-V. The air-entraining cement CEM II/B-V was produced using two methods: mixed together with natural or synthetic aerated admixture. The air volume test of the volumetric method was carried out in case of fresh cement paste, mortar and concrete mix. Fresh concretes were evaluated in terms of stability of air entrainment and consistency for 5, 20 and $40 \mathrm{~min}$. The porosity structure parameters, like summarized aircontent, specific surface of air voids, air-voids spacing factor and micropores content of hardened concrete, were estimated using computed tomography with a resolution of 2-5 $\mu \mathrm{m}$. The aim of the research was to determine the dependence between air-content of cement paste, mortar and concrete on the measurement of air-entrainment of cement paste or mortar with the same w/c ratio and type of cement, all designed according to PN-EN 480-1 guidelines. Test results proved that there is a good correlation between the measured air-content of the cement paste, mortar and concrete. Therefore, it is possible to predict the aeration of concrete on the air-entrainment of the mortar.
\end{abstract}

Keywords: air-entraining admixture, air-content, cement, mortar, concrete, porosity.

\section{Introduction}

In order to maintain better durability performance and extended service life in freezing and thawing environments, concrete should have an adequate air-void. For this, a suitable amount of entrained air-voids with accurate specific surface and spacing factor should be ensured. Commonly, limits on the volume of air-voids or air content are specified although the role of spacing factor is important. This is due to the fact that the air content can be determined more effortlessly and immediately than spacing factor [1]. This type of air entrainment is desired for freeze-thaw protection. To accomplish this, air-entraining agents are used to entraining or better stabilize the required air.

The type of air-entraining admixture influences significantly the porosity values of concrete parameters. Research results presented in publication [2] proved that the natural admixture aeration is more powerful than the synthetic one because the natural admixture participation is much smaller than the synthetic in cement. Generally, the more water in the 
volume of concrete, the more air bubbles are formed [3]. It is not known which type of admixture entraining is less sensitive to changes in the quantities of water in the concrete.

Moreover, cement type is an important factor for achieving proper porosity of concrete [4]-[6]. Most problems with appropriate air-entrainment take place in concretes with fly ash cement. The main reason is that the coke in fly ash with a developed specific surface (loss of ignition) may absorb on its surface the surface-active factor, thereby decreasing its effectiveness. Therefore, a higher amount of air-entrainment admixture may be required in order to achieve the same degree of air-entrainment. Furthermore, if the distribution of coke in concrete is irregular, areas of different air content may occur. Fly ash, even in small quantities reduces natural air content by about 1\%. Although Fagerlund [7], [8] proposed that for concrete with air-entrainment the effect of fly ash is negligible, provided that its content does not exceed $25 \%$ (ACI 218-95 recommends the reduction of puzzolan to the value of $25 \%$ ). However, if the distribution of unburned coke in concrete is uneven, then the areas of different air content may occur. Accordingly, he proposes a higher dosage of air-entrainment admixture. It is worth indicating the types of cement - apart from CEM I - recommended in an XF environment. For example, in environmental classes XF2 and XF4, the Austrian Standard qualifies cement CEM II/A-V as "recommended", while the German Standard qualifies this cement as "not recommended".

Thus, designing aeration of concrete is complicated, because it depends on the type of cement and, above all, on the amount of water relative to the cement. Determining the amount of air-entraining admixture on the concrete laboratory test is cost-intensive and time-consuming work. A certain simplification in this area would be the creation of the possibility of aerating the concrete on the basis of the air-entraining test of cement paste or mortar, made of the same materials like concrete. Of course, while maintaining the same other technological parameters, above all the mortar and concrete temperature. The present study is an experimental analysis of the relationship between air-volume in air-entrained cement paste, mortar and plastic and hardened concrete, all designed according to PN-EN 480-1 [9] is presented in the paper. The cement paste, mortar and concrete, with $\mathrm{w} / \mathrm{c}=0,5$ ratio, were prepared using innovative airentraining cement CEM II/B-S, incorporating natural or synthetic air-entraining admixture.

\section{Experimental procedure}

In the first stage of the research, fresh pastes and mortars with innovative air-entraining cement were evaluated. These cement mortars were made of air-entraining innovative with natural or synthetic air-entraining admixture (AEA) (Tables 1, 2 and 3), sand acc. EN 196-1; water (Table 4). With these materials, standardized cement mortar with $\mathrm{w} / \mathrm{c}=0.50$ was prepared, in accordance with the recommendations of PN-EN 480-1 [9]. The consistency of the mortars was determined according to PN-EN 1015-3 [10], while the air-content according to PN-EN 1015-7 [11]. The proper amount of air-entraining admixture in air-entraining cement was investigated based on air-content measurements in concrete mix acc. EN 480-1. Then, aircontent in mortar acc. EN 480-1 was indicated. For all cement types, our measurement of different air-content in concrete mix and mortar were compared.

In the second stage of the research, fresh concrete mix with innovative air-entraining cement were evaluated (Table 5) in terms of stability of air entrainment and consistency of 
mortar for 5, 20 and $40 \mathrm{~min}$. The concrete mix was prepared acc. to PN-EN 480-1. Ambient temperature during fresh concrete testing was $20^{\circ} \mathrm{C} \pm 1^{\circ} \mathrm{C}$. The relative air humidity was about $50 \%$. The air-content of fresh concrete mix according to PN-EN 480-1 [9] was investigated according to PN-EN 12350-7:2009 [12]. The consistency of fresh concrete was investigated according to PN-EN 12350-2 [13]. The stability of air entrainment and consistency of concrete was checked for 5, 20 and $40 \mathrm{~min}$.

Table 1 . The amount of admixture from the cement type

\begin{tabular}{|c|c|c|c|}
\hline $\begin{array}{l}\text { The method of } \\
\text { producing } \\
\text { cement: mixed } \\
\text { with admixture } \\
\text { (m), co-ground } \\
\text { with admixture } \\
\text { (cg). }\end{array}$ & $\begin{array}{l}\text { Type of air- } \\
\text { entraining } \\
\text { admixture } \\
\text { (AEA) S - } \\
\text { synthetic, N- } \\
\text { natural }\end{array}$ & AEA, \% m.C. & Symbol of air-entraining cement \\
\hline $\mathrm{m}$ & $S$ & 0,600 & CEM I (S) \\
\hline $\mathrm{m}$ & $\mathrm{N}$ & 0,035 & CEM I (N) \\
\hline $\mathrm{cg}$ & S & 0,400 & CEM I (S) \\
\hline $\mathrm{cg}$ & $\mathrm{N}$ & 0,030 & CEM I (N) \\
\hline $\mathrm{m}$ & $\mathrm{S}$ & 0,850 & CEM II/B-V (S) \\
\hline $\mathrm{m}$ & $\mathrm{N}$ & 0,060 & CEM II/B-V (N) \\
\hline $\operatorname{cg}$ & $\mathrm{S}$ & 1,700 & CEM II/B-V (S) \\
\hline $\mathrm{cg}$ & $\mathrm{N}$ & 0,120 & CEM II/B-V (N) \\
\hline $\mathrm{m}$ & S & 0,560 & CEM II/B-S (S) \\
\hline $\mathrm{m}$ & $\mathrm{N}$ & 0,023 & CEM II/B-S (N) \\
\hline $\mathrm{cg}$ & $\mathrm{S}$ & 0,600 & CEM II/B-S (S) \\
\hline $\mathrm{cg}$ & $\mathrm{N}$ & 0,030 & CEM II/B-S (N) \\
\hline $\mathrm{m}$ & S & 0,290 & CEM III/A (S) \\
\hline $\mathrm{m}$ & $\mathrm{N}$ & 0,020 & CEM III/A (N) \\
\hline $\mathrm{cg}$ & S & 0,560 & CEM III/A (S) \\
\hline $\mathrm{cg}$ & $\mathrm{N}$ & 0,040 & CEM III/A (N) \\
\hline $\mathrm{m}$ & S & 0,330 & CEM III/A-NA (S) \\
\hline $\mathrm{m}$ & $\mathrm{N}$ & 0,019 & CEM III/A-NA (N) \\
\hline $\mathrm{cg}$ & $S$ & 0,245 & CEM III/A-NA (S) \\
\hline $\operatorname{cg}$ & $\mathrm{N}$ & 0,024 & CEM III/A-NA (N) \\
\hline $\mathrm{m}$ & $S$ & 0,350 & CEM V/A (S-V) S \\
\hline $\mathrm{m}$ & $\mathrm{N}$ & 0,091 & CEM V/A $(\mathrm{S}-\mathrm{V}) \mathrm{N}$ \\
\hline $\mathrm{cg}$ & S & 2,350 & CEM V/A (S-V) S \\
\hline $\mathrm{cg}$ & $\mathrm{N}$ & 0,117 & CEM V/A $(\mathrm{S}-\mathrm{V}) \mathrm{N}$ \\
\hline $\mathrm{m}$ & $S$ & 1,380 & CEM V/B (S-V) S \\
\hline $\mathrm{m}$ & $\mathrm{N}$ & 0,105 & CEM V/B $(\mathrm{S}-\mathrm{V}) \mathrm{N}$ \\
\hline $\operatorname{cg}$ & $\mathrm{S}$ & 2,000 & CEM V/B (S-V) S \\
\hline $\mathrm{w}$ & $\mathrm{N}$ & 0,140 & CEM V/B (S-V) N \\
\hline
\end{tabular}


Table 2. Percentage of additives along with the weight of CEM I 52.5

\begin{tabular}{|c|c|c|c|c|c|c|}
\hline $\begin{array}{l}\text { Cement } \\
\text { type }\end{array}$ & $\begin{array}{l}\text { Production } \\
\text { method }\end{array}$ & $\begin{array}{c}\text { Clinker } \\
1\end{array}$ & Clinker 2 & $\begin{array}{l}\text { Blast-furnace } \\
\text { granulated slag }\end{array}$ & $\begin{array}{c}\text { Silica fly } \\
\text { ash }\end{array}$ & $\begin{array}{l}\text { Binding } \\
\text { regulator* }\end{array}$ \\
\hline \multirow[t]{2}{*}{ CEM I } & Mixing & - & $100 \%$ & 0 & 0 & 0,0 \\
\hline & Grinding & 93,3 & - & 0 & 0 & 6,7 \\
\hline CEM & Mixing & - & 65,5 & 0 & 33 & 1,5 \\
\hline II/B-V & Grinding & 62 & - & 0 & 33 & 5,0 \\
\hline CEM & Mixing & - & 65,5 & 33 & 0 & 1,5 \\
\hline II/B-S & Grinding & 62 & - & 33 & 0 & 5,0 \\
\hline CEM & Mixing & - & 45,5 & 53 & 0 & 1,5 \\
\hline III/A & Grinding & 41,5 & - & 53 & 0 & 5,5 \\
\hline CEM & Mixing & - & 32 & 65 & 0 & 3,0 \\
\hline III/A-NA & Grinding & 29 & - & 65 & 0 & 6,0 \\
\hline CEM & Mixing & - & 43,3 & 27,5 & 27,5 & 1,7 \\
\hline V/A & Grinding & 39 & - & 27,5 & 27,5 & 6,0 \\
\hline CEM & Mixing & - & 22 & 44 & 31 & 3,0 \\
\hline $\mathrm{V} / \mathrm{B}$ & Grinding & 20 & - & 44 & 31 & 5,0 \\
\hline
\end{tabular}

Notes: * addition of a binding regulator that provides the number of sulphates in the amount $2,8-3,1 \% \mathrm{SO}_{3}$.

Table 3. The properties of air-entraining cement components

\begin{tabular}{lllll}
\hline Feature & Clinker 1 & Clinker $2^{* *}$ & $\begin{array}{l}\text { Blast-furnace } \\
\text { granulated slag }\end{array}$ & Silica fly ash \\
\hline $\begin{array}{l}\text { Loss on ignition } \\
\mathrm{SiO}_{2}\end{array}$ & 0,15 & 0,64 & $+0,40$ & 2,26 \\
$\mathrm{Al}_{2} \mathrm{O}_{3}$ & 21,95 & 20,8 & 38,24 & 54,20 \\
$\mathrm{Fe}_{2} \mathrm{O}_{3}$ & 4,70 & 5,18 & 5,99 & 26,81 \\
$\mathrm{CaO}$ & 3,14 & 2,94 & 1,01 & 5,62 \\
$\mathrm{MgO}$ & 66,60 & 63,9 & 44,99 & 3,03 \\
$\mathrm{SO}$ & 1,20 & 1,38 & 6,52 & 0,82 \\
$\mathrm{~K}_{2} \mathrm{O}$ & 0,42 & 4,61 & 0,88 & 0,34 \\
$\mathrm{Na}_{2} \mathrm{O}$ & 0,62 & 0,73 & 0,56 & 2,92 \\
$\mathrm{Content}$ of the & 0,24 & 0,12 & 0,51 & 0,61 \\
vitreous phase & - & - & $99 \%$ & - \\
Fineness & - & - & - & $32 \%$
\end{tabular}

Notes: * Cement reference for the production of mixed air-entraining cement - cement CEM I ** Cement reference for the production of multi-component air-entraining cement 
Table 4. Paste or mortar composition, gram.

\begin{tabular}{llll}
\hline Type of cement mixture & $\begin{array}{l}\text { Amount } \\
\text { of cement }\end{array}$ & $\begin{array}{l}\text { Amount } \\
\text { of water }\end{array}$ & $\begin{array}{l}\text { Standard sand acc. to PN } \\
\text { EN 196-1 }\end{array}$ \\
\hline paste & 1350.0 & 675.0 & - \\
mortar & 450.0 & 225.0 & 1350.0 \\
modified mortar & 900.0 & 500.0 & 1350.0 \\
\hline
\end{tabular}

Table 5. The concrete components; $\mathrm{kg} / \mathrm{m}^{3}$.

\begin{tabular}{|c|c|c|c|c|c|}
\hline $\begin{array}{l}\text { Symbol } \\
\text { of concrete }\end{array}$ & Cement & Water & $\begin{array}{l}\text { Sand } \\
0-2 \mathrm{~mm}\end{array}$ & $\begin{array}{l}\text { Crushed } \\
\text { gravel } \\
2-8 \mathrm{~mm}\end{array}$ & $\begin{array}{l}\text { Crushed } \\
\text { gravel } \\
8-16 \mathrm{~mm}\end{array}$ \\
\hline VN1 & 350.00 & 175.00 & 522.00 & 511.90 & 853.10 \\
\hline
\end{tabular}

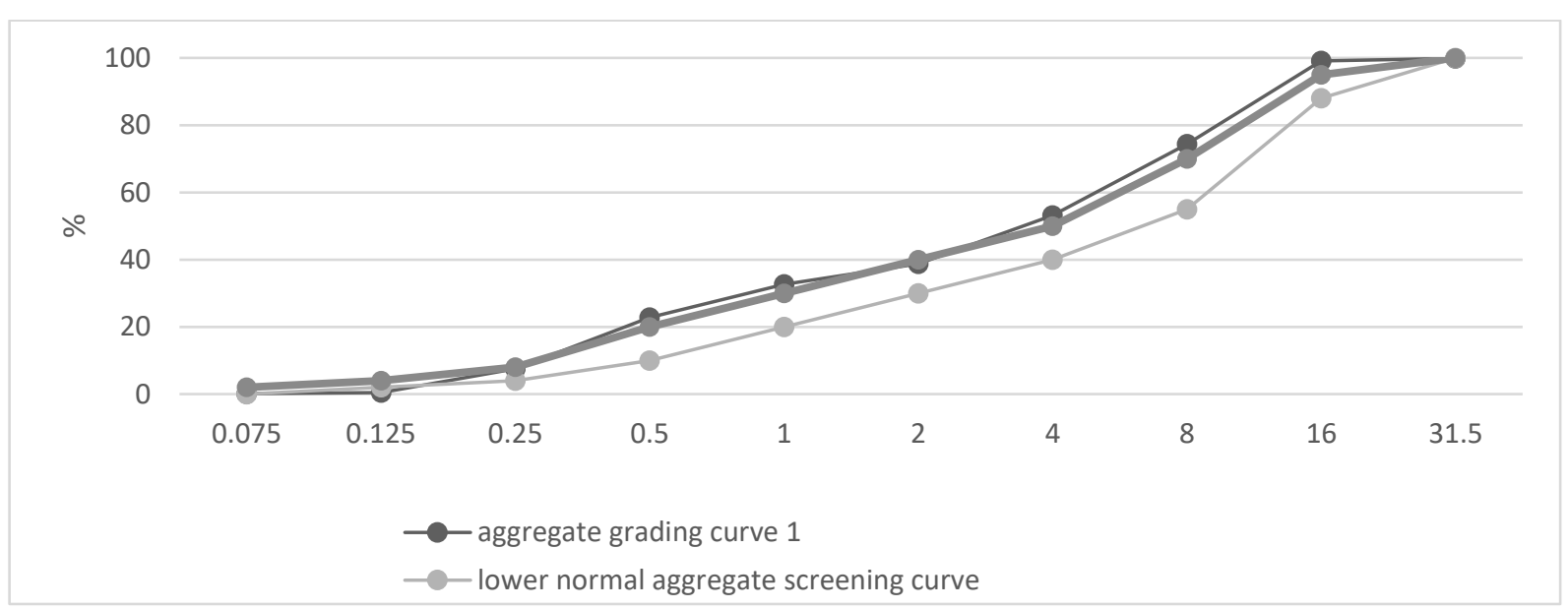

Fig. 1. Aggregate grading curve 1

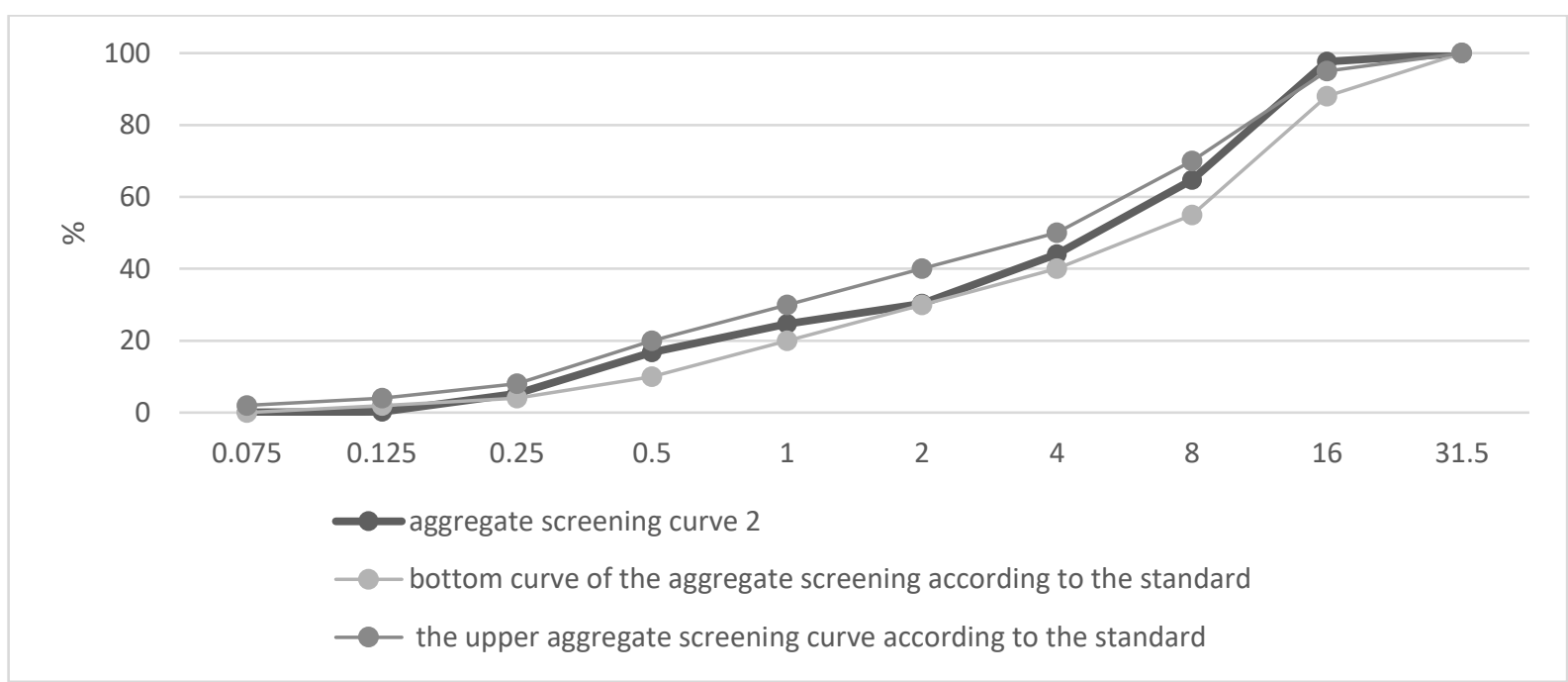

Fig. 2. Aggregate grading curve 2

In the third stage of the research the porosity of hardened concrete acc. PN-EN 480-1 with air-entraining CEM II/B-V (Table 5) was investigated. The porosity structure parameters of the air-entrained concrete according to PN-EN 480-11 [14] with air-entraining CEM II/B-V 
were estimated. Porosity parameters of concrete were obtained from the processing of computed tomography (CT) scanned images. Tomographic studies of samples were performed using a CT scanner: v/tome/x m - firm's GE. The CT scanner was equipped with a detector panel and projection system using the X-ray beam which is formed into a cone.

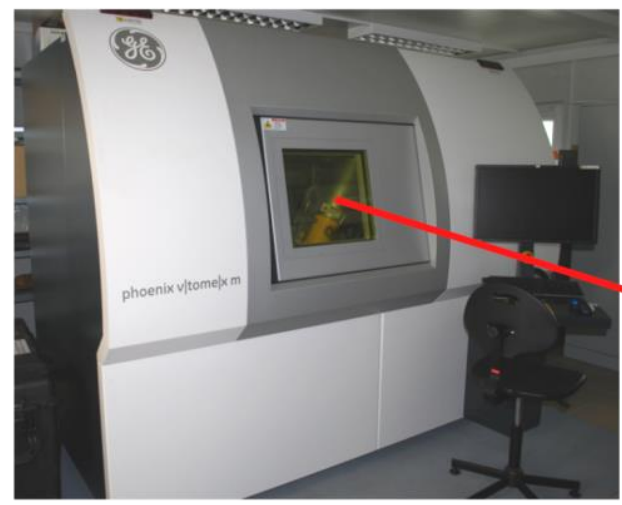

a)

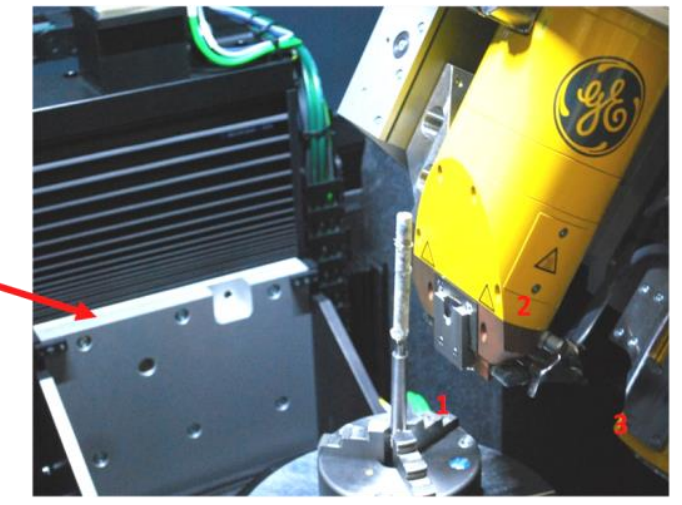

b)

Fig. 3. The view of computer tomograph V/Tome/x firm's GE a) general view b) view in the middle, 1 - a table with the sample, 2,3 - X-ray tubes [on the basis of materials of the Air Force Institute of Technology].

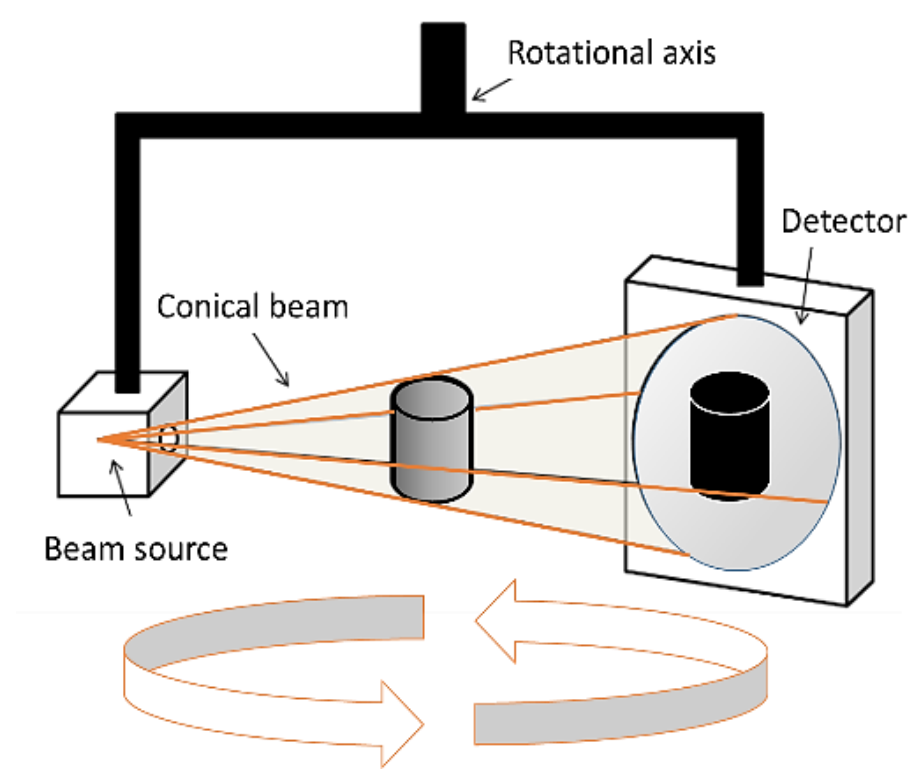

Fig. 4. Diagram of the conical beam [on the basis of materials of the Air Force Institute of Technology].

Tomographic studies conducted on drill core samples (with a diameter of $10 \mathrm{~mm}$ ) which were taken from the cubic size $15 \times 15 \times 15 \mathrm{~cm}$ (Figures 5-7). On the basis of digital image analysis of drilled concrete core, the structure parameters of air voids were determined by the means of a computer program. The example of a cross-section of the sample for further analysis is shown in Figs 3 and 4. 

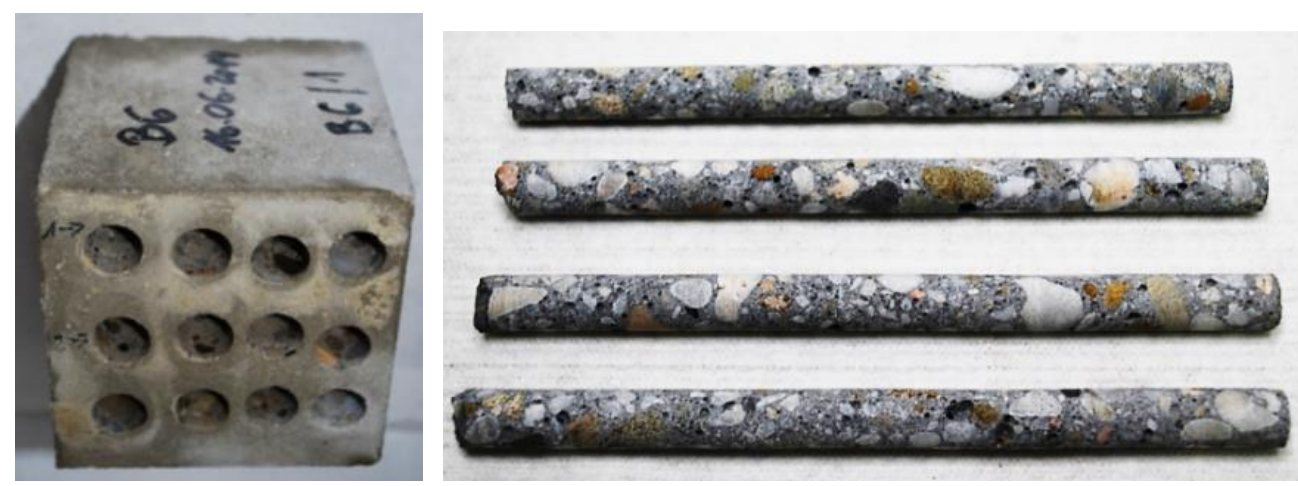

Fig. 5. Method of obtaining the drilling concrete Figure 6. Example of drilling concrete

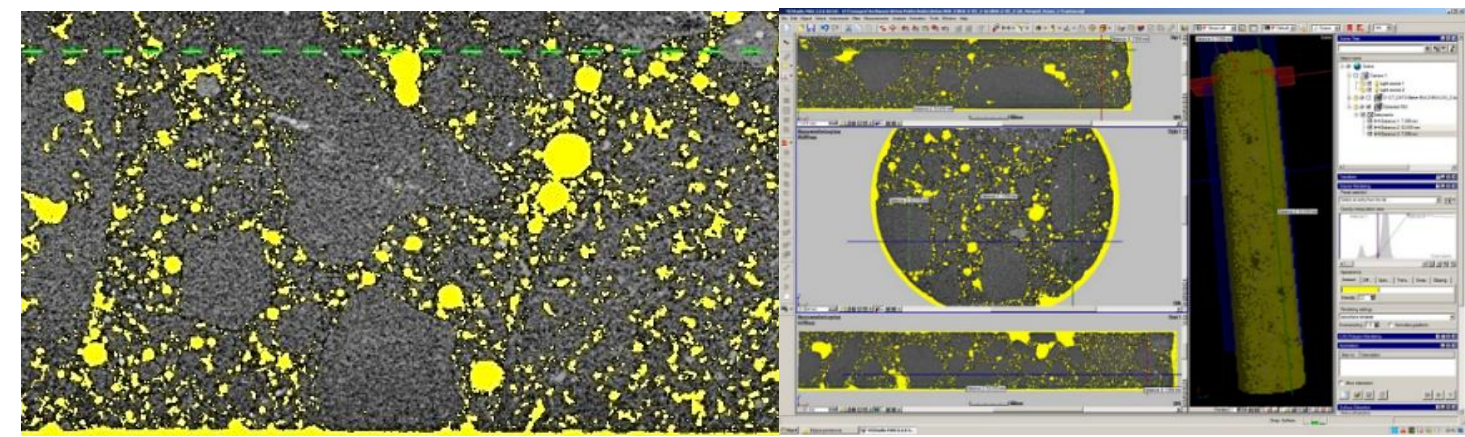

Fig. 7. Figure 8 . The image section of the concrete core obtained using CT software (air pores are marked in the yellow - screenshot

\section{Results and discussions}

The 6-12 tables summarised the results of air content testing in constipation with the airentraining cement. It has been shown that the amount of aeration admixture has been established correctly in order to obtain adequate air-content of concrete mixtures (see Fig. 10).

Table 6. The content of the air in the brew of the type of air-entraining cement CEM I

\begin{tabular}{ccccc}
\hline Cement & $\begin{array}{c}\text { Established air } \\
\text { content in the } \\
\text { mortar, } \%\end{array}$ & $\begin{array}{c}\text { Type of } \\
\text { admixture }\end{array}$ & $\begin{array}{c}\text { Additive } \\
\text { admixtures } \\
\% \text { m.c. }\end{array}$ & $\begin{array}{c}\text { Air content in the } \\
\text { mortar, } \%\end{array}$ \\
\hline CEM I (N) cg & 10.0 & Natural & 0.030 & 10.0 \\
CEM I (N) m & 11.0 & Natural & 0.035 & 11.0 \\
CEM I (S) cg & 10.0 & Synthetic & 0.400 & 10.0 \\
CEM I (S) m & 11.0 & Synthetic & 0.600 & 11.0 \\
\hline
\end{tabular}


Table 7. The content of the air in the brew of the type of air-entraining cement CEM II/B-V

\begin{tabular}{ccccc}
\hline Cement & $\begin{array}{c}\text { Established } \\
\text { air content in } \\
\text { the mortar, \% }\end{array}$ & $\begin{array}{c}\text { Type of } \\
\text { admixture }\end{array}$ & $\begin{array}{c}\text { Additive } \\
\text { admixtures } \\
\% \text { m.c. }\end{array}$ & $\begin{array}{c}\text { Air content in the } \\
\text { mortar, \% }\end{array}$ \\
\hline CEM II/B-V (N) cg & 10.5 & Natural & 0.120 & 10.5 \\
CEM II/B-V (N) m & 10.0 & Natural & 0.060 & 10.0 \\
CEM II/B-V (S) cg & 10.5 & Synthetic & 1.700 & 10.5 \\
CEM II/B-V (S) m & 9.4 & Synthetic & 0.850 & 9.4 \\
\hline
\end{tabular}

Table 8. The content of the air in the brew of the type of air-entraining cement CEM II/B-S

\begin{tabular}{ccccc}
\hline Cement & $\begin{array}{c}\text { Established } \\
\text { air content in } \\
\text { the mortar, \% }\end{array}$ & $\begin{array}{c}\text { Type of } \\
\text { admixture }\end{array}$ & $\begin{array}{c}\text { Additive } \\
\text { admixtures } \\
\% \text { m.c. }\end{array}$ & $\begin{array}{c}\text { Air content in the } \\
\text { mortar, \% }\end{array}$ \\
\hline CEM II/B-S (N) cg & 11.7 & Natural & 0.030 & 11.2 \\
CEM II/B-S (N) m & 9.5 & Natural & 0.023 & 9.4 \\
CEM II/B-S (S) cg & 11.5 & Synthetic & 0.600 & 11.5 \\
CEM II/B-S (S) m & 9.8 & Synthetic & 0.420 & 10.0 \\
\hline
\end{tabular}

Table 9. The content of the air in the brew of the type of air-entraining cement CEM III/A

$\begin{array}{cccc}\text { Established } & \text { Type of } & \text { Additive } & \text { Air content in the } \\ \text { air content in } & \text { admixtures } & \text { mortar, } \%\end{array}$

\begin{tabular}{lcccc}
\hline CEM III/A (N) cg & 10.5 & Natural & 0.040 & 10.5 \\
CEM III/A (N) m & 8.2 & Natural & 0.020 & 8.2 \\
CEM III/A (S) cg & 10.5 & Synthetic & 0.560 & 10.5 \\
CEM III/A (S) m & 9.0 & Synthetic & 0.290 & 8.8 \\
\hline
\end{tabular}

Table 10. The content of the air in the brew of the type of air-entraining cement CEM III/ANA

\begin{tabular}{|c|c|c|c|c|}
\hline Cement & $\begin{array}{c}\text { Establis } \\
\text { hed air } \\
\text { content } \\
\text { in the } \\
\text { mortar, } \\
\%\end{array}$ & $\begin{array}{l}\text { Type of } \\
\text { admixture }\end{array}$ & $\begin{array}{c}\text { Additive } \\
\text { admixtures } \\
\% \text { m.c. }\end{array}$ & $\begin{array}{c}\text { Air content in the } \\
\text { mortar, } \%\end{array}$ \\
\hline CEM III/A-NA (N) cg & 10.5 & Natural & 0.024 & 10.5 \\
\hline CEM III/A-NA (N) m & 8.2 & Natural & 0.019 & 8.0 \\
\hline CEM III/A-NA (S) cg & 10.5 & Synthetic & 0.245 & 10.2 \\
\hline CEM III/A-NA (S) m & 8.8 & Synthetic & 0.350 & 8.6 \\
\hline
\end{tabular}


Table 11. The content of the air in the brew of the type of air-entraining cement CEM III/ANA

\begin{tabular}{ccccc}
\hline Cement & $\begin{array}{c}\text { Established } \\
\text { air content } \\
\text { in the } \\
\text { mortar, } \%\end{array}$ & $\begin{array}{c}\text { Type of } \\
\text { admixture }\end{array}$ & $\begin{array}{c}\text { Additive } \\
\text { admixtures } \\
\% \text { m.c. }\end{array}$ & $\begin{array}{c}\text { Air content in the } \\
\text { mortar, \% }\end{array}$ \\
\hline CEM V/A (N) cg & 10.8 & Natural & 0.117 & 10.8 \\
CEM V/A (N) m & 10.5 & Natural & 0.091 & 10.2 \\
CEM V/A (S) cg & 11.0 & Synthetic & 2.350 & 11.0 \\
CEM V/A (S) m & 10.0 & Synthetic & 1.380 & 10.0 \\
\hline
\end{tabular}

Table 12. The content of the air in the brew of the type of air-entraining cement CEM III/ANA

\begin{tabular}{ccccc}
\hline Cement & $\begin{array}{c}\text { Established } \\
\text { air content } \\
\text { in the } \\
\text { mortar, } \%\end{array}$ & $\begin{array}{c}\text { Type of } \\
\text { admixture }\end{array}$ & $\begin{array}{c}\text { Additive } \\
\text { admixtures } \\
\% \text { m.c. }\end{array}$ & $\begin{array}{c}\text { Air content in the } \\
\text { mortar, \% }\end{array}$ \\
\hline CEM V/B (N) cg & 10.0 & Natural & 0.140 & 9.9 \\
CEM V/B (N) m & 10.5 & Natural & 0.105 & 10.3 \\
CEM V/B (S) cg & 10.0 & Synthetic & 2.000 & 10.0 \\
CEM V/B (S) m & 10.5 & Synthetic & 1.330 & 10.6 \\
\hline
\end{tabular}

In Figs. 8-10 the influence of air-entraining cement type on air-entraining admixture demand is presented. The highest demand for an aerating admixture is in the case of CEM V/A (S-V), CEM V/B (S-V) and CEM II/B-V due to the highest proportion of fly ash in the cement (Fig. 8 and 9), regardless of the air-entraining admixture type and technology of cement preparation. The smallest demand is in the case of cement CEM III/A and CEM III/A-NA. Cement with a large proportion of granulated blast furnace slag is best also stabilizes air-content of concrete (Figs. 17 and 18). Similar to the analysed test results were obtained in the publication [4]. It has been proven that as the ash grows in the mortar, the percentage of air is reduced. Similarly to the results obtained by authors, it was proved that the higher value for cement mortar with CEM III/A. 


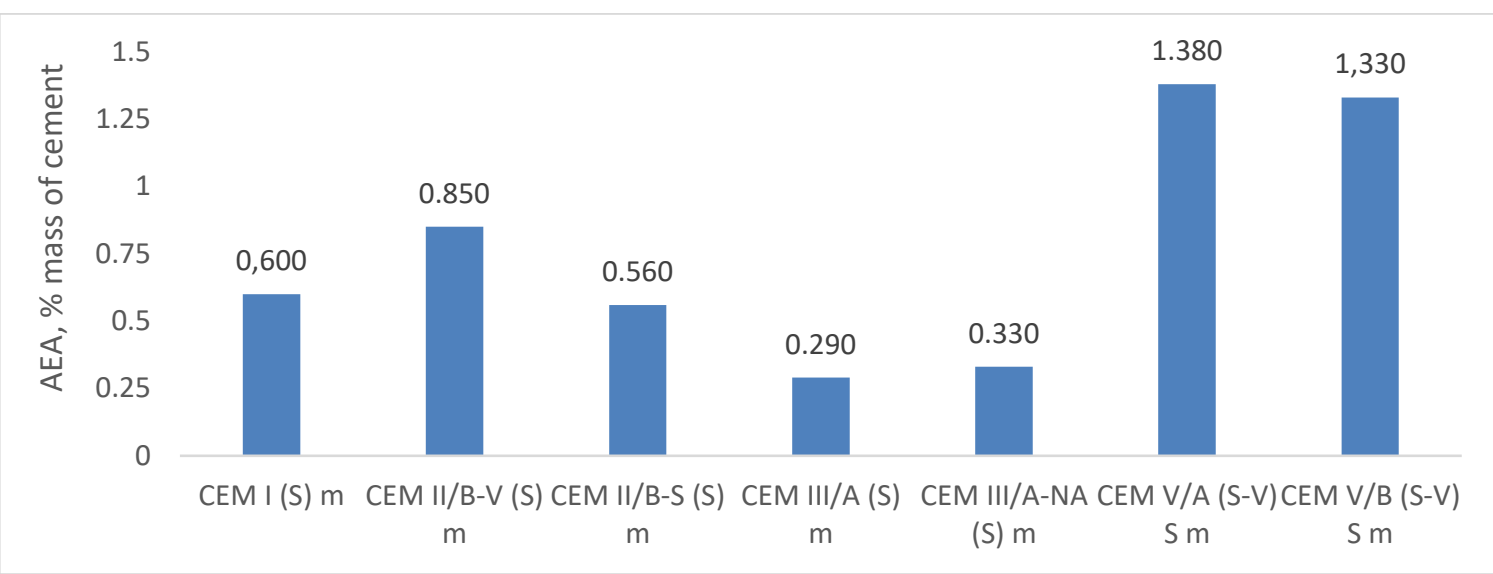

Fig. 8. The influence of cement type on synthetic air-entraining admixture demand

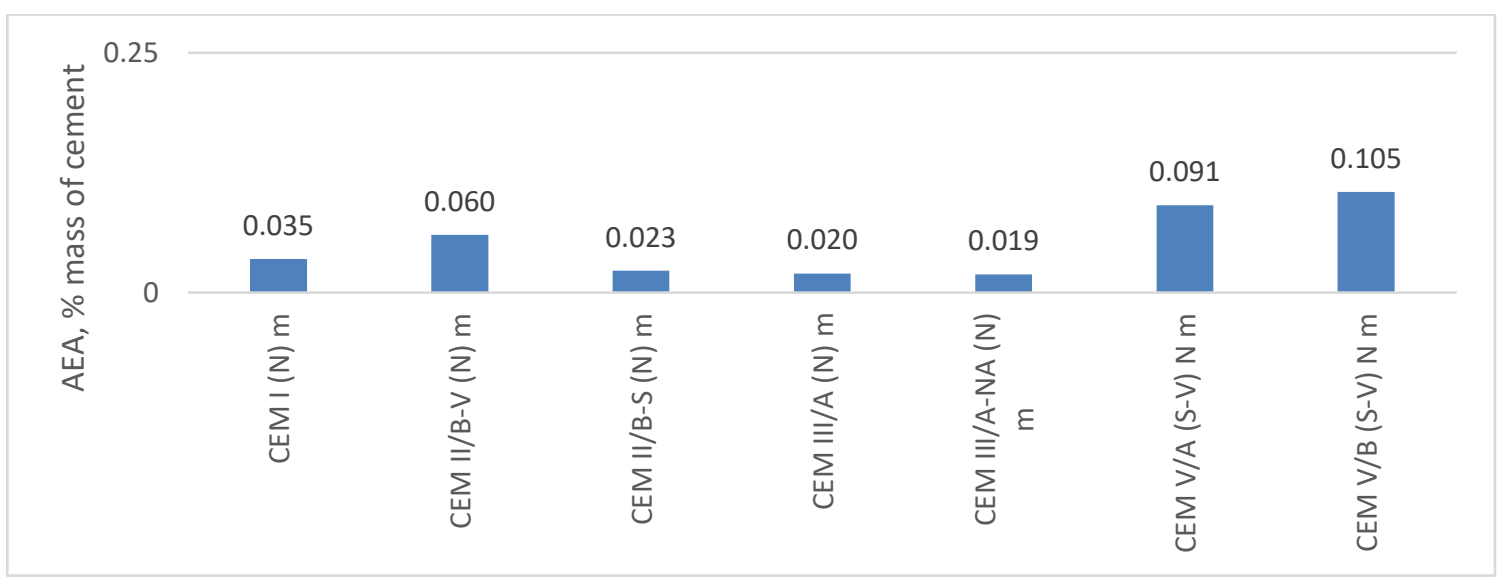

Fig. 9. The influence of cement type on natural air-entraining admixture demand

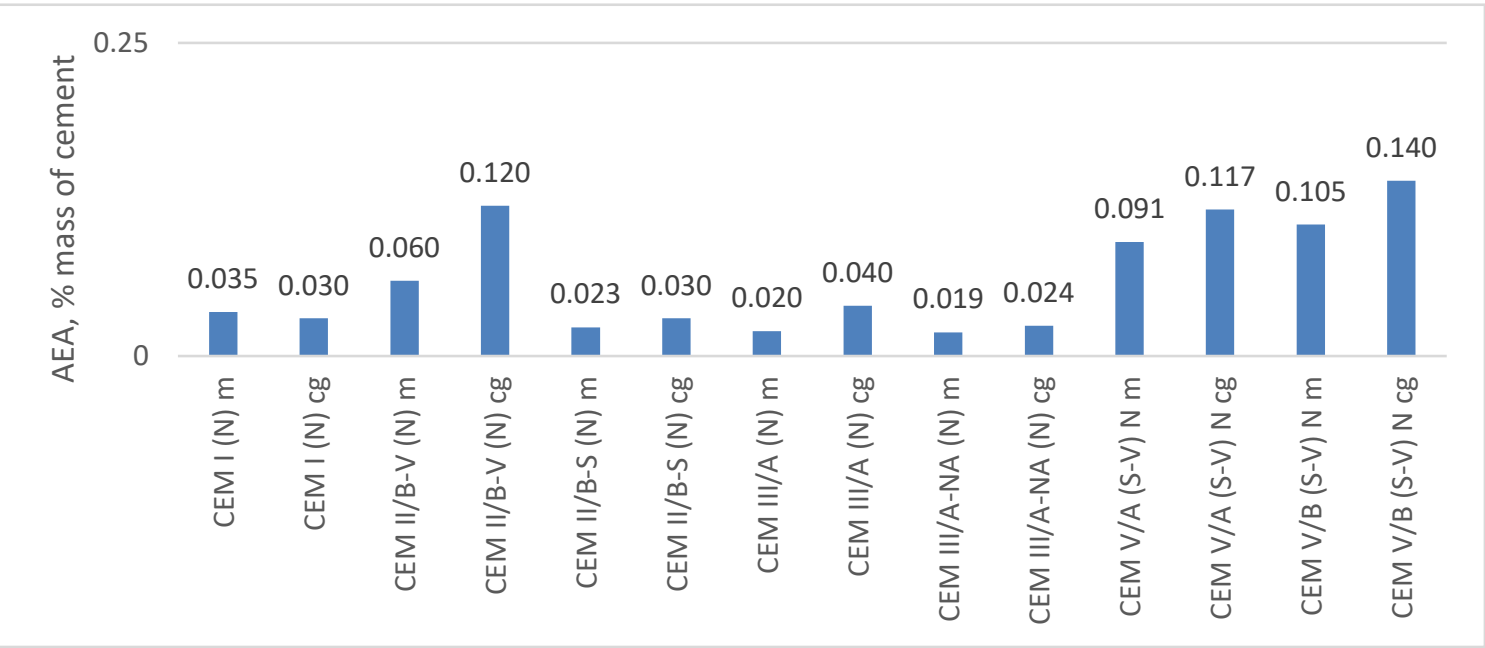

Fig. 9. The influence of methodology preparing and cement type on natural air-entraining admixture demand 


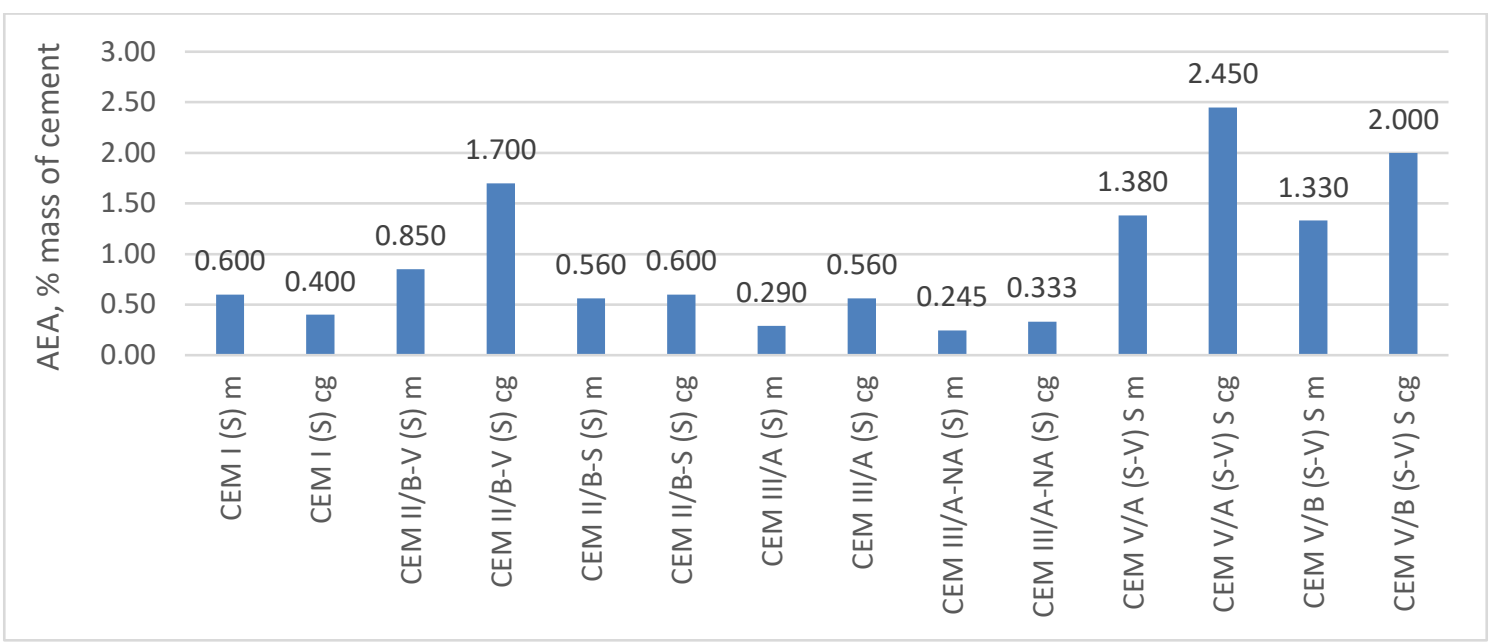

Fig. 10. The influence of methodology preparing and cement type on synthetic air-entraining admixture demand

These results presented in Figs 1 and 2 prove that there is a strong correlation between the air content in the mortar and plastic concrete mix. The air content in the cement paste corresponds to about twice the air content in the concrete mix. Therefore, it can be assumed that air-content of the plastic concrete mix according to PN-EN 480-1 can be predicted on the basis of an air-content test of mortar according to PN EN 480-1 (made of the same cement and w/c ratio and the same temperature as concrete). The mortar volume in concrete is $48,49 \%$ (Table 5), that corresponds with the relation between air content in mortar and concrete (in mortar acc. EN 480-1 is double volume air content than in concrete acc. EN 480-1). In publication Error! Reference source not found. the effect of mortar volume on the air content of concrete was also noticed. This publication also proved the strong correlation suggests that the AEA dosage needed for a target air content in concrete can be determined based on the equivalent air content of its mortar phase. To predict air-content in concrete modified mortar should be used (Table 4), with double paste volume than acc. EN 480-1, that prove research results presented in Fig. 12. 


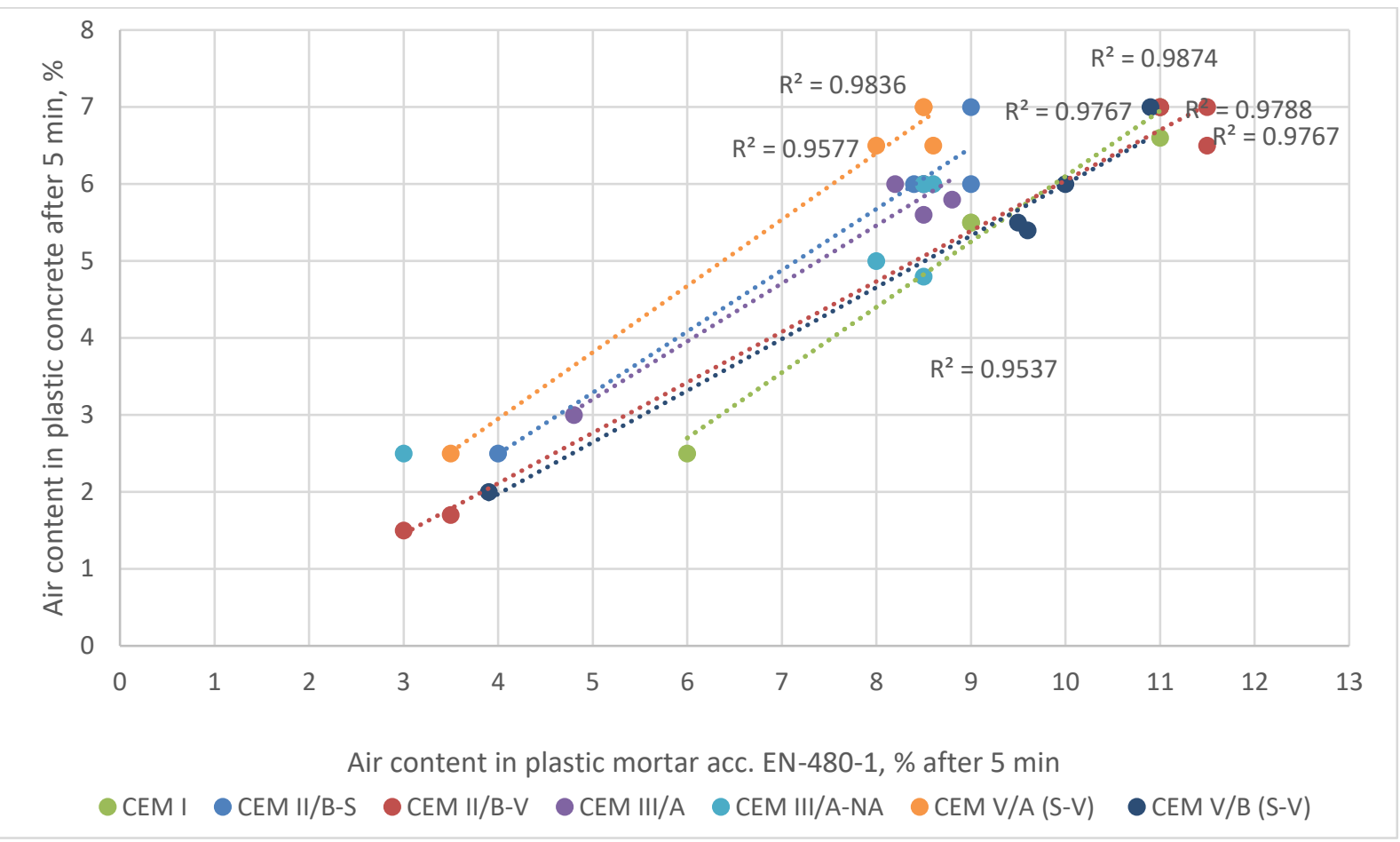

Fig. 11. The relationship between the air content in cement paste, mortar and fresh concrete, regardless of the type of air-entraining admixture.

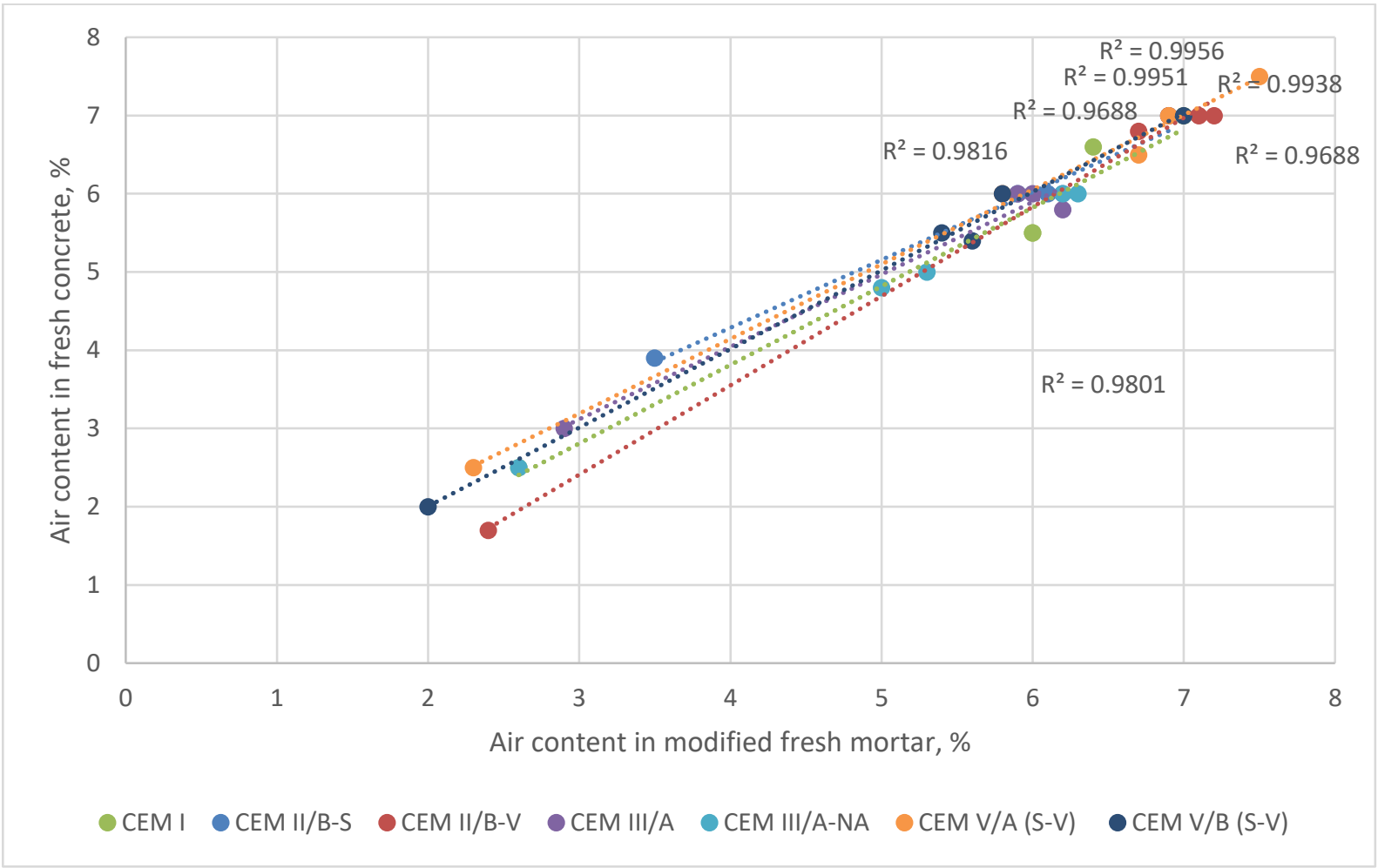

Fig. 12. The relationship between the air content in the modified mortar (with double paste volume than in mortar acc. EN 480-1 - Table 5) and fresh concrete, regardless of the type of air-entraining admixture. 
The characteristics and grading of aggregates have also a significant influence on air entrainment. In paste, it is more difficult to entrain air because the entrained air is affected by buoyancy and there are no particles that can trap the air bubbles. In mortar and concrete, because of the addition of aggregates, the fine aggregates can form a space to hold the air bubbles and prevent them from escaping. Furthermore, aggregate with a sharp shape, like crushed stone, will entrain less air than gravel. The sharper the aggregate is the harder for the air bubbles to attach on it [25]. Research results presented in Fig. 12 prove that the aggregate granulometry influence strongly on the air content in the concrete mixture. Air content decreases with the increased fineness of cementitious materials. Fine aggregates can entrain more air than coarse aggregates. For aggregate grading curve 1 the air content is concrete is higher than for concrete with aggregate grading curve no. 2, because the aggregate grading curve 1 characterise bigger specific volume of grains (compare Figs 1 and 2). Research results [23] indicate that aggregate particle form has no significant impact on the quantity of entrained air in concrete mixture. Nevertheless, data presented in Fig. 12 proves that specific volume of aggregate is important factor for achieving adequate air-volume in the concrete mix. There is another important factor to predict porosity of concrete. For example, the mixing method is also important factor to the porosity of concrete [24]. The two-step mixing process (mixing mortar first, then adding coarse aggregate) produced a lower air void spacing factor than the one-step (four-minute) mixing method (mixing all concrete materials together at once) and the ASTM mixing method. For concrete mixed with the one-step mixing method, the air void spacing factor reduced with mixing time. For a given concrete mix and mixing procedure, use of different sizes of pan mixers, time of mixing provided the mixtures with different air contents and spacing factors. As mentioned above, air bubbles in concrete are firstly entrained by the mixing process. Hence, the mixing is an important factor which together with the aggregates can affect air entrainment in concrete, since the large air bubbles can be split into smaller ones by the movement of aggregates in the mixer.

From the viewpoint of work and energy, the formation of air bubbles in fresh concrete can be explained as follows: The mixing action gives the energy to the fresh concrete to create the interface between air and water and form the large air voids and then split them into small voids. However, there is a tendency that the small air voids coalesce into larger ones. From the energy viewpoint for the same volume of air, the one contains small air voids has a larger specific surface area and therefore, higher energy than the one with large air voids, the latter can always more easily escape from the paste due to its larger buoyant force. So the mixing action (mixer, mixing time, revolution rate, etc.), can affect how much energy can be turned into free surface energy of the air bubbles which balance the surface tension of the air bubbles. For example, mixing with longer time can, of course, entrain more air in fresh concrete by applying for more work on the paste [25].

The air-content of mortar acc. EN 480-1 should be between 9 and 11 per cent of the air content in order to complement 4 to 7 per cent of the air content in concrete acc. EN 480-1. However, in the case of CEM III/A, a smaller range of the recommended amount of air, from 8 to 9 per cent. The correlation between the aeration of constipation and concrete is significantly influenced by the particle. A similar observation was obtained in publication [23]. As can be 
seen in Figure 13, the relationship described is almost straight, depending on the proportion of aggregates of the given dimension (Figs. 1 and 2)

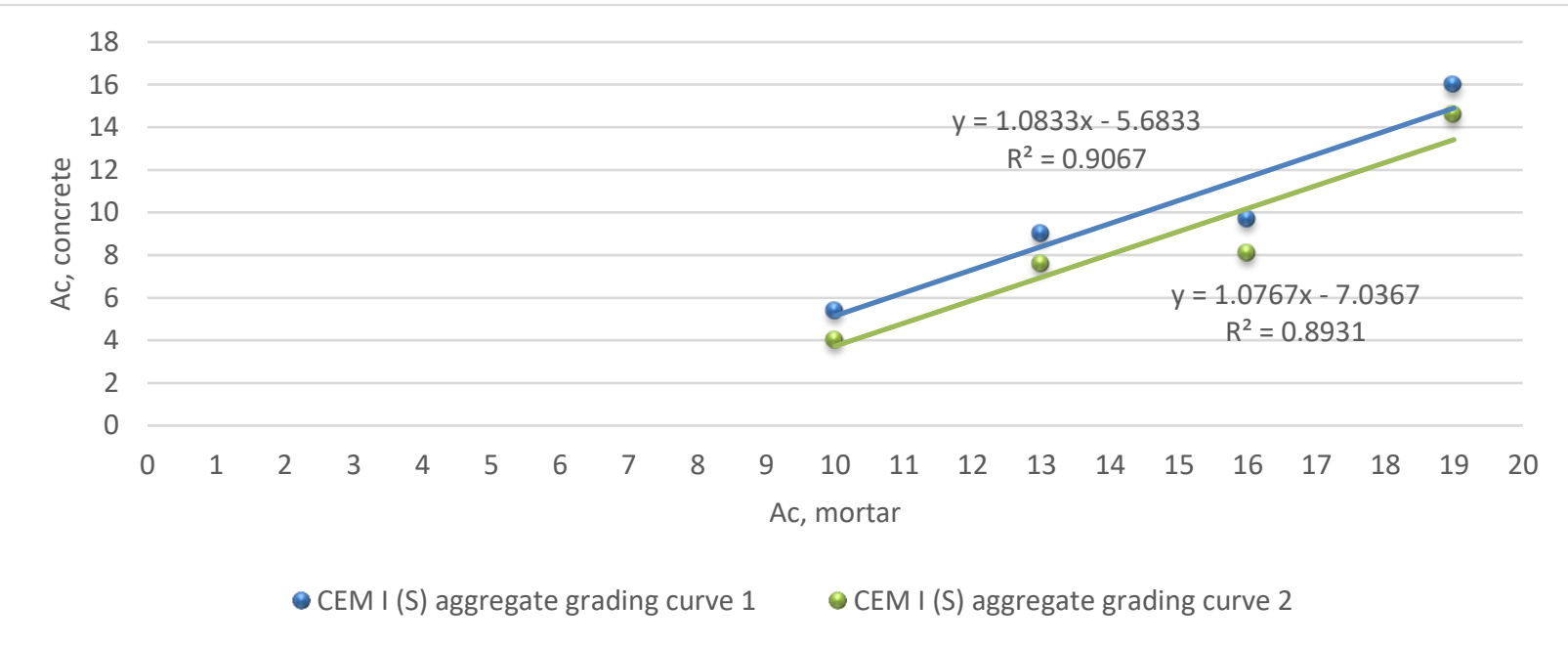

Fig. 13. The relation between air-content in mortar and concrete with aggregate grading curve no. 1 and 2 (Figs 1 and 2).

Nevertheless, it is possible to predict air-content in fresh concrete based on air-content indicated in mortars (made from the same of cement type, w/c ratio and with similar temperature), that was presented in Figs 11 and 12.

The change in the air content over time and the consistency of the concrete mix is shown in Figures 12-25. The lower air content value of the concrete mix after 40 minutes does not correspond to lower air content in the hardened concrete (Fig. 26-31) since this is in most cases even higher than was measured during the first measurement in the concrete mix. This proves the high stability of aeration of concrete despite the presence of fly ash. The change of airentrainment and consistency of concrete mix in time is not dependent on the type of airentraining admixture (Figure 12 to Figure 25).

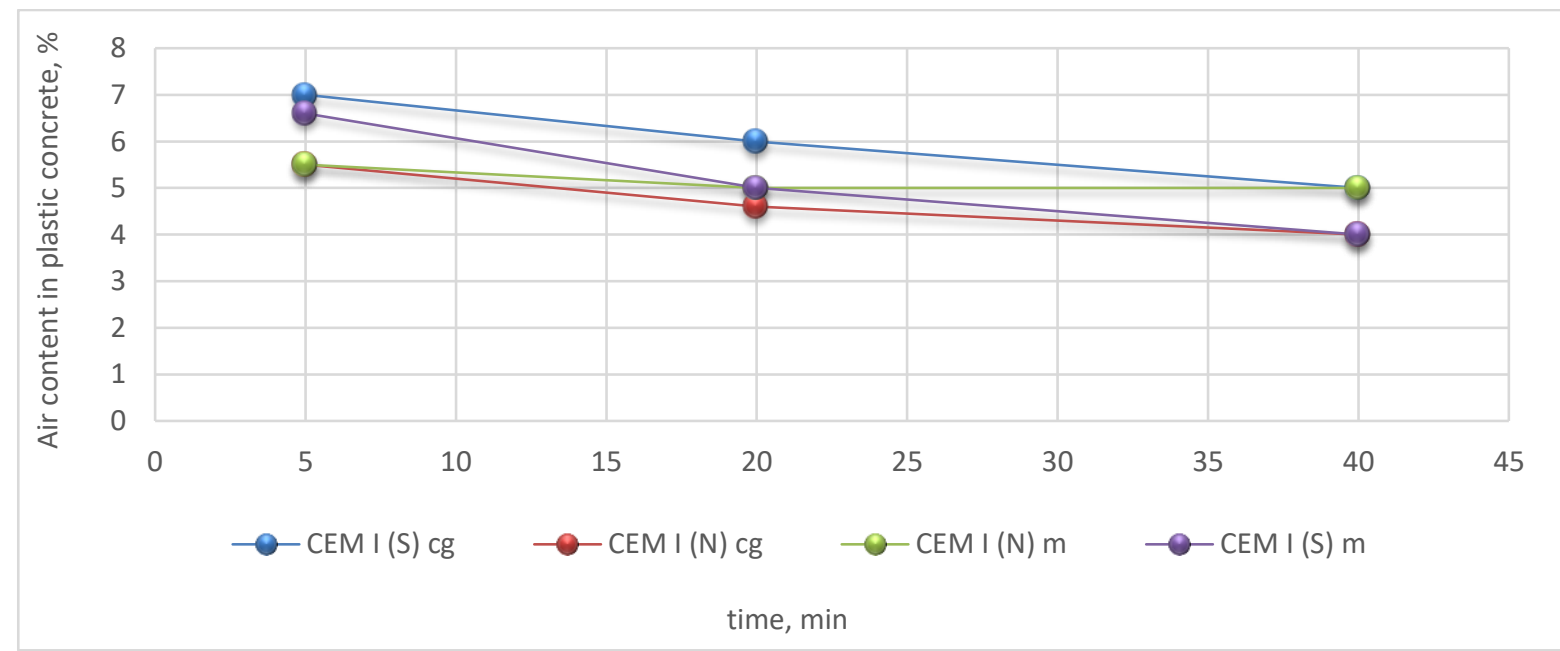

Fig. 14. Air content in fresh concrete with CEM I after 5, 20 and 40 minutes. 


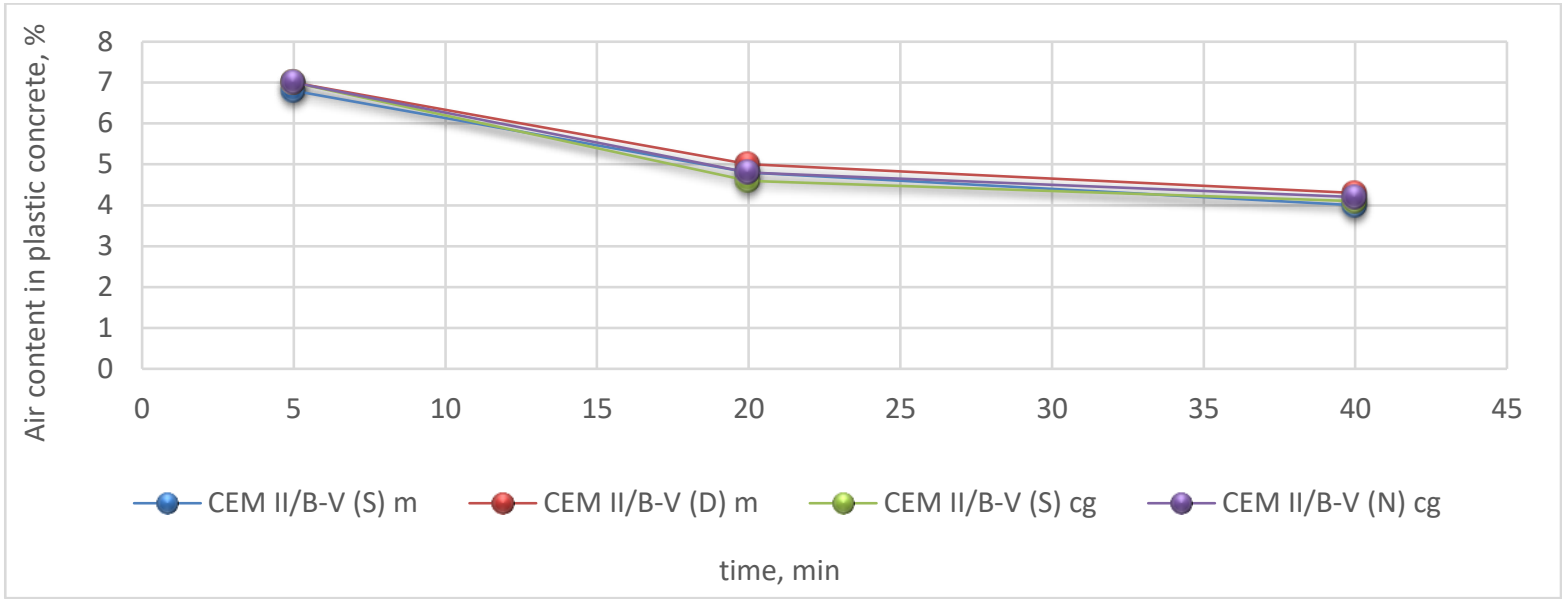

Fig. 15. Air content in fresh concrete with CEM II/B-V after 5, 20 and 40 minutes.

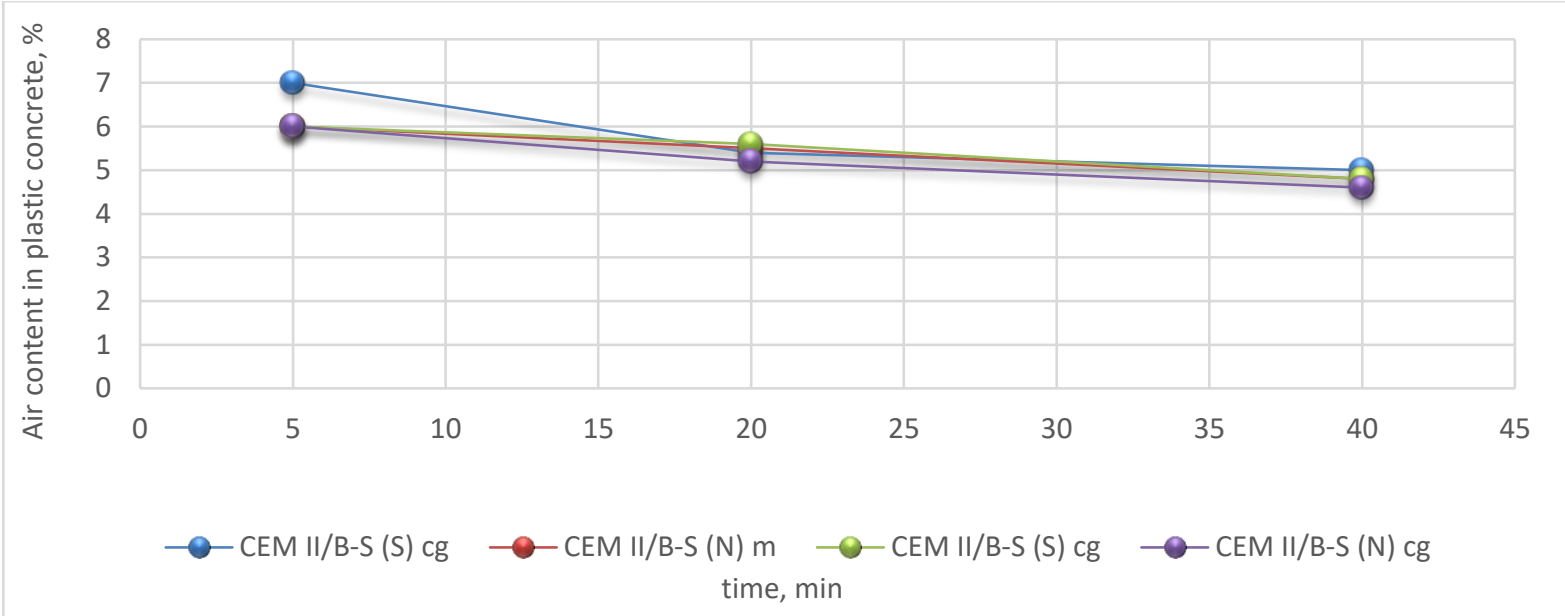

Fig. 16. Air content in fresh concrete with CEM II/B-S after 5, 20 and 40 minutes.

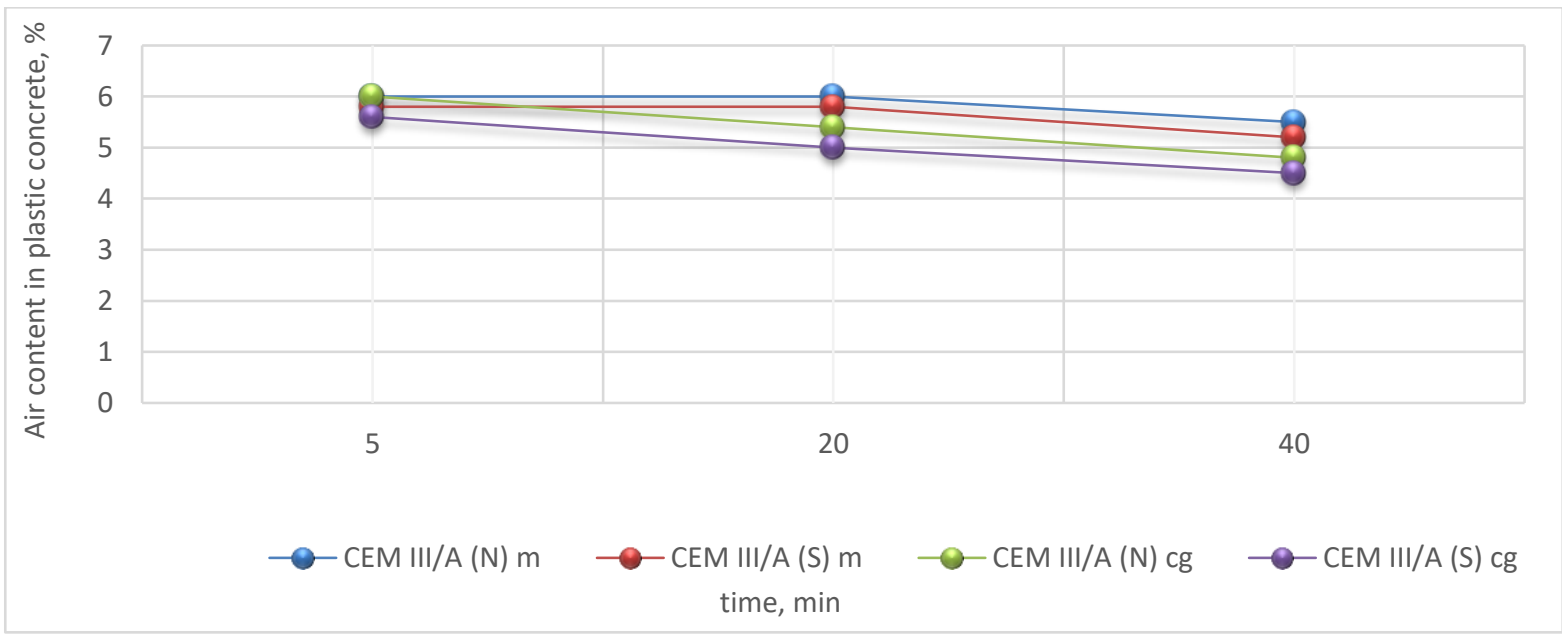

Fig. 17. Air content in fresh concrete with CEM III/A after 5, 20 and 40 minutes. 


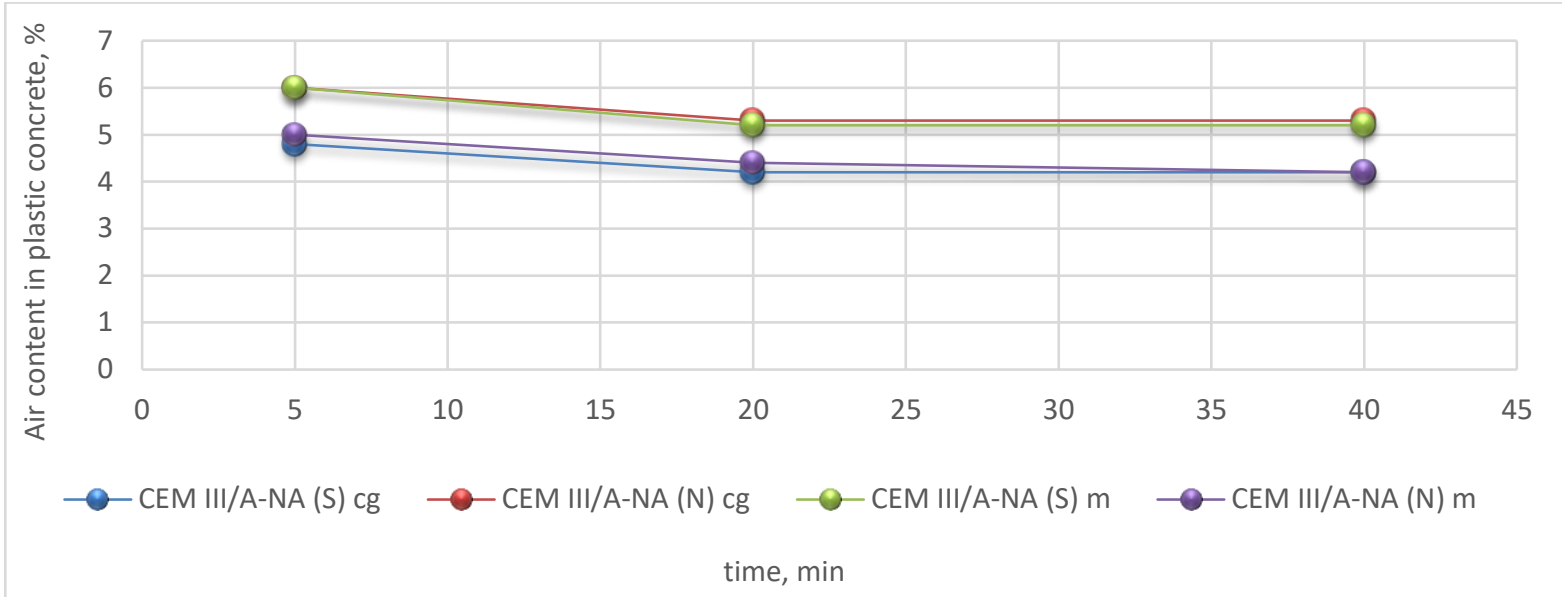

Fig. 18. Air content in fresh concrete with CEM III/A-NA after 5, 20 and 40 minutes.

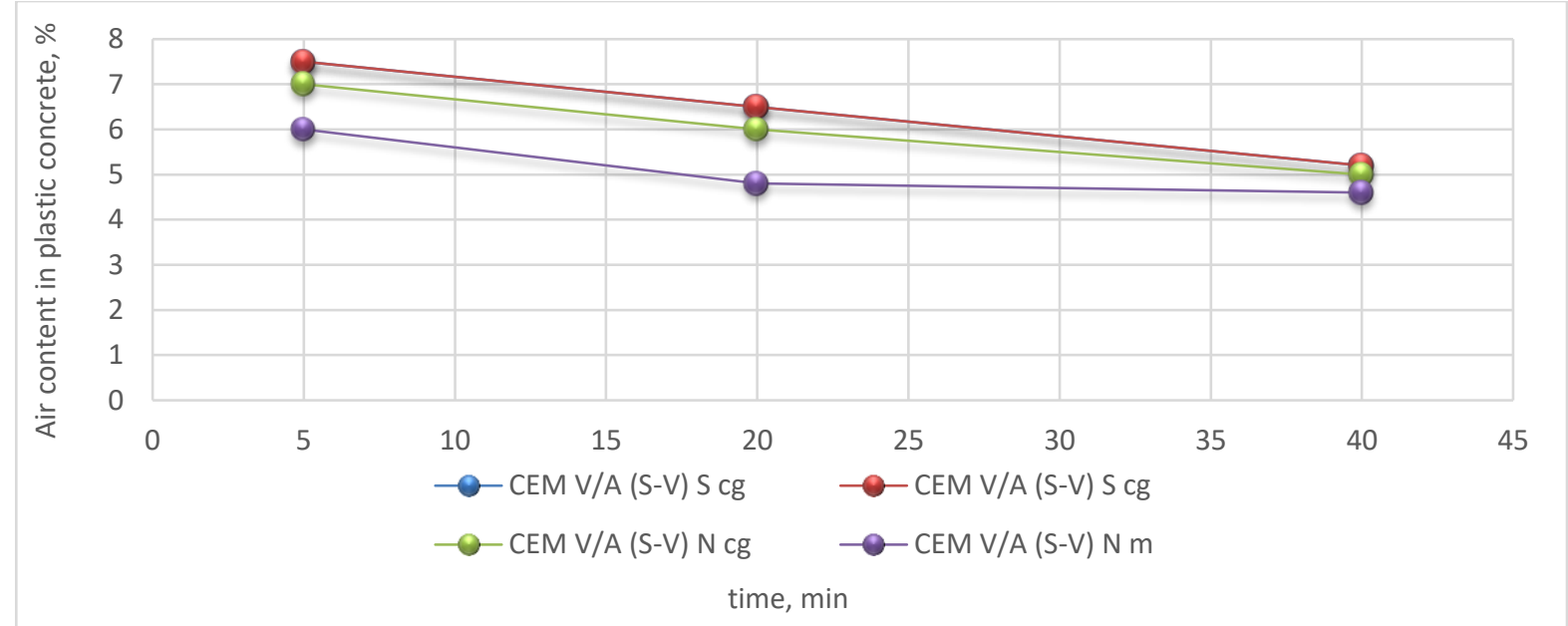

Fig. 19. Air content in fresh concrete with CEM V/A (S-V) after 5, 20 and 40 minutes.

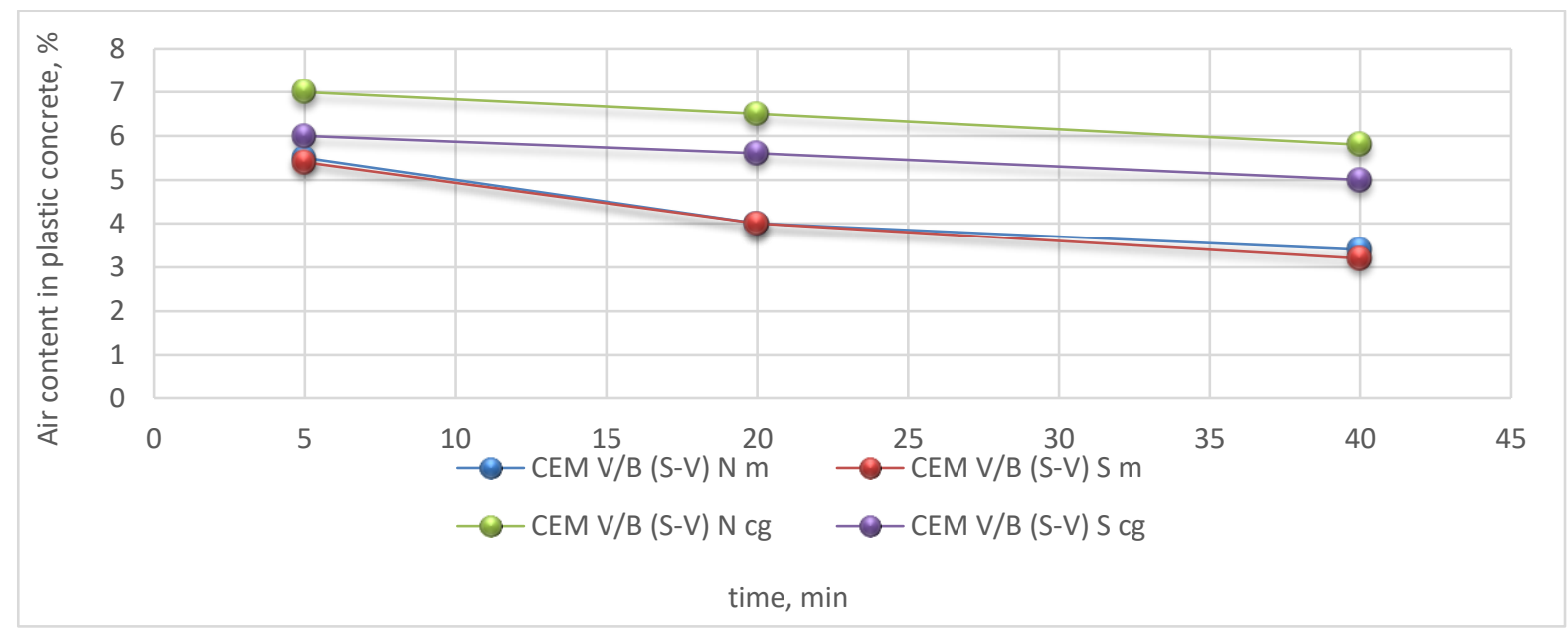

Fig. 20. Air content in fresh concrete with CEM V/B (S-V) after 5, 20 and 40 minutes. 


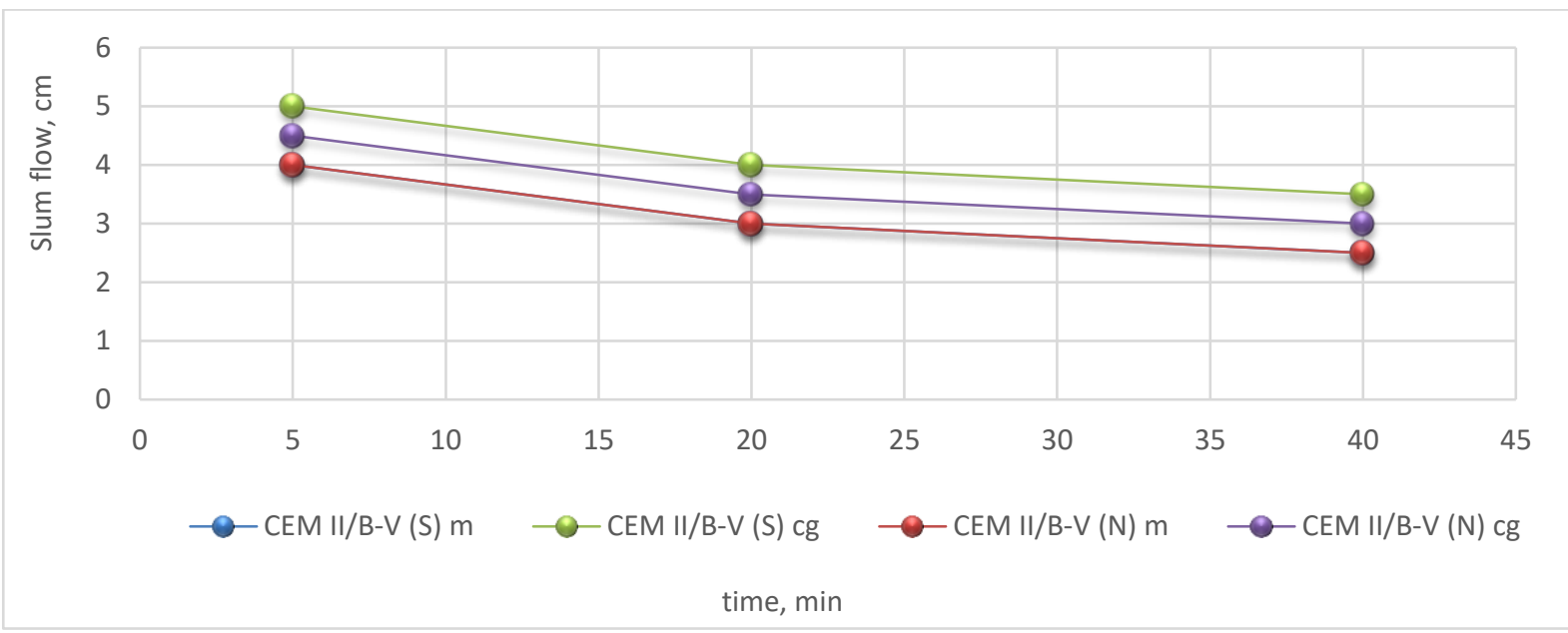

Fig. 21. Consistency of fresh concrete with CEM II/B-V after 5, 20 and 40 minutes.

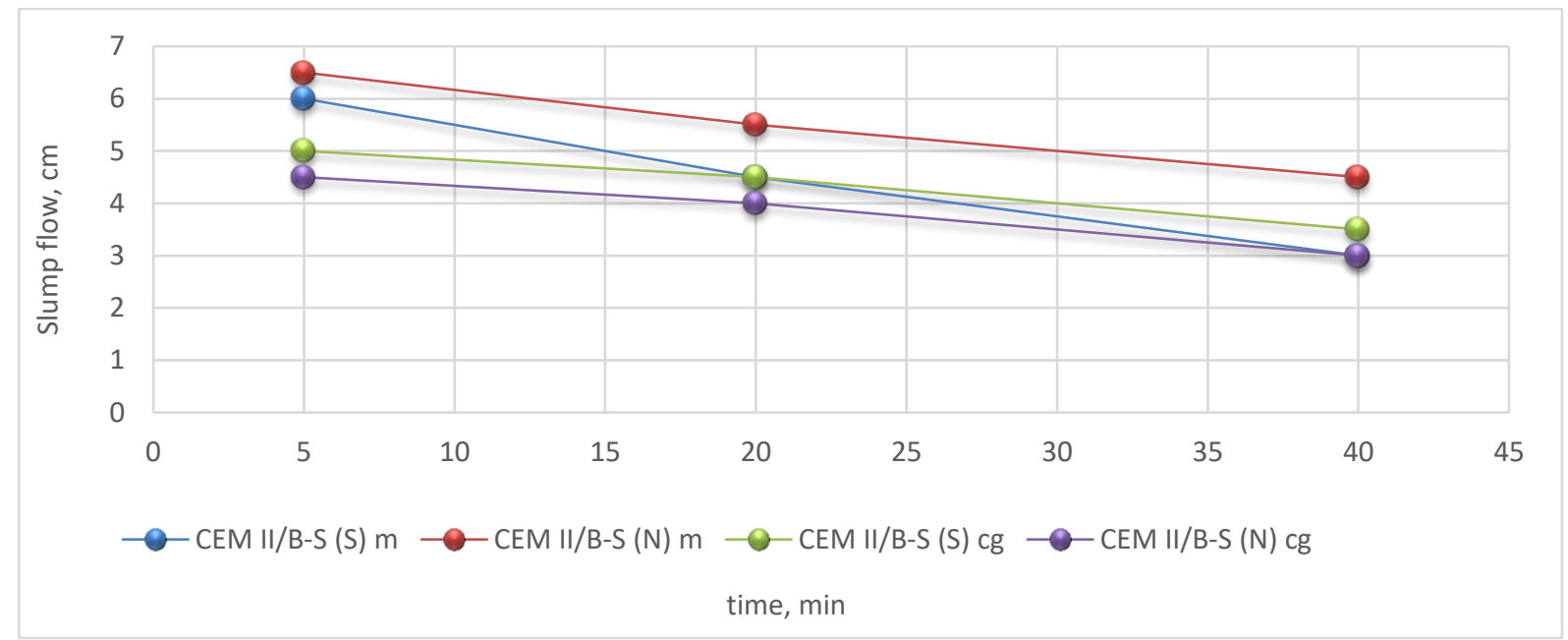

Fig. 22. Consistency of fresh concrete with CEM II/B-S after 5, 20 and 40 minutes.

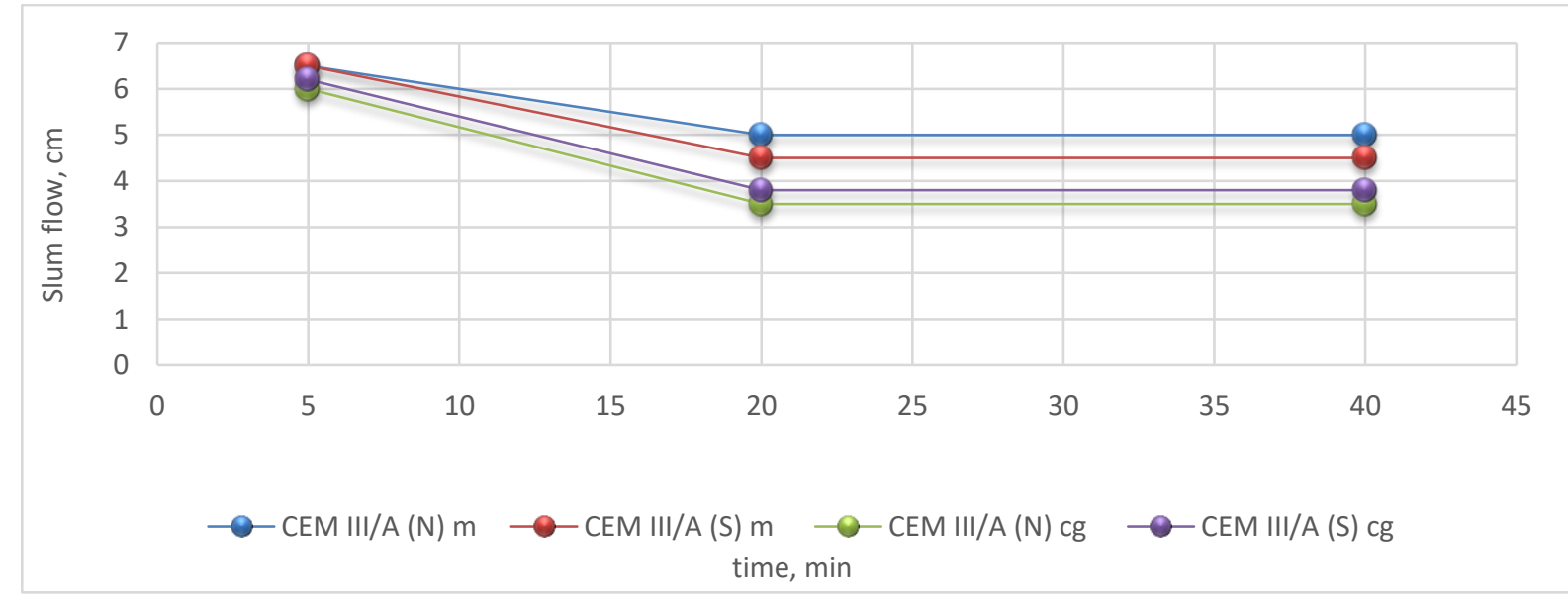

Fig. 23. Consistency of fresh concrete with CEM III/A after 5, 20 and 40 minutes. 


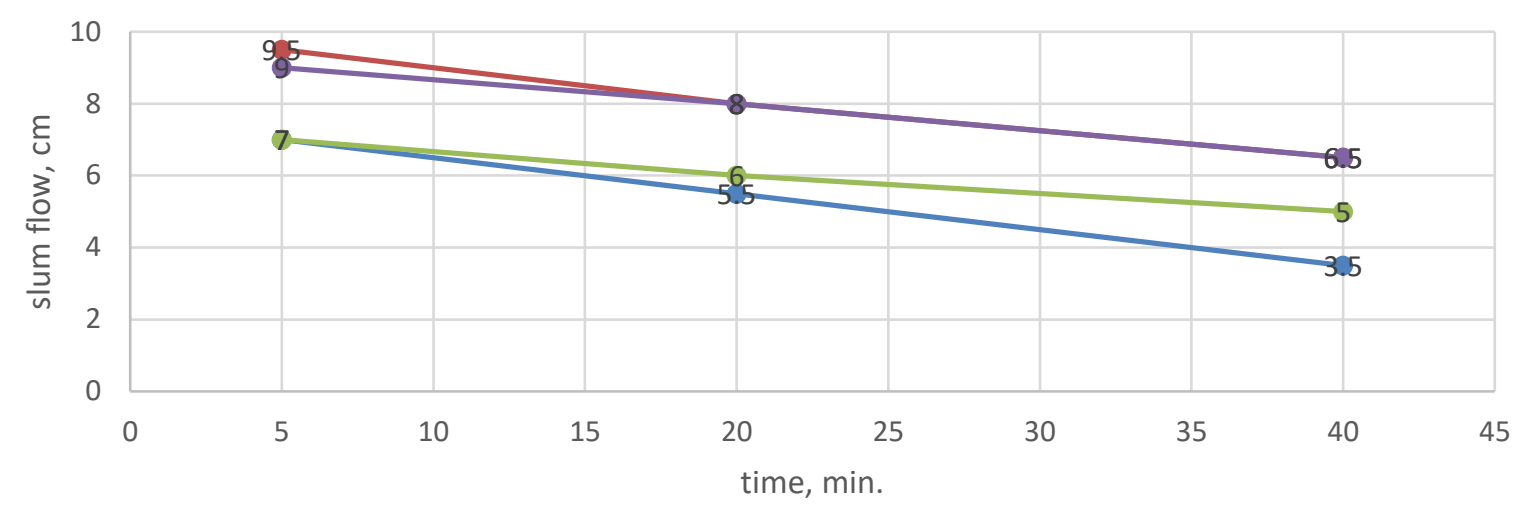

$\longrightarrow$ CEM V/A (S-V) N cg $\longrightarrow$ CEM V/A (S-V) S cg $\longrightarrow$ CEM V/A (S-V) N m $\longrightarrow$ CEM V/A (S-V) S m

Fig. 24. Consistency of fresh concrete with CEM V/A (S-V) after 5, 20 and 40 minutes.

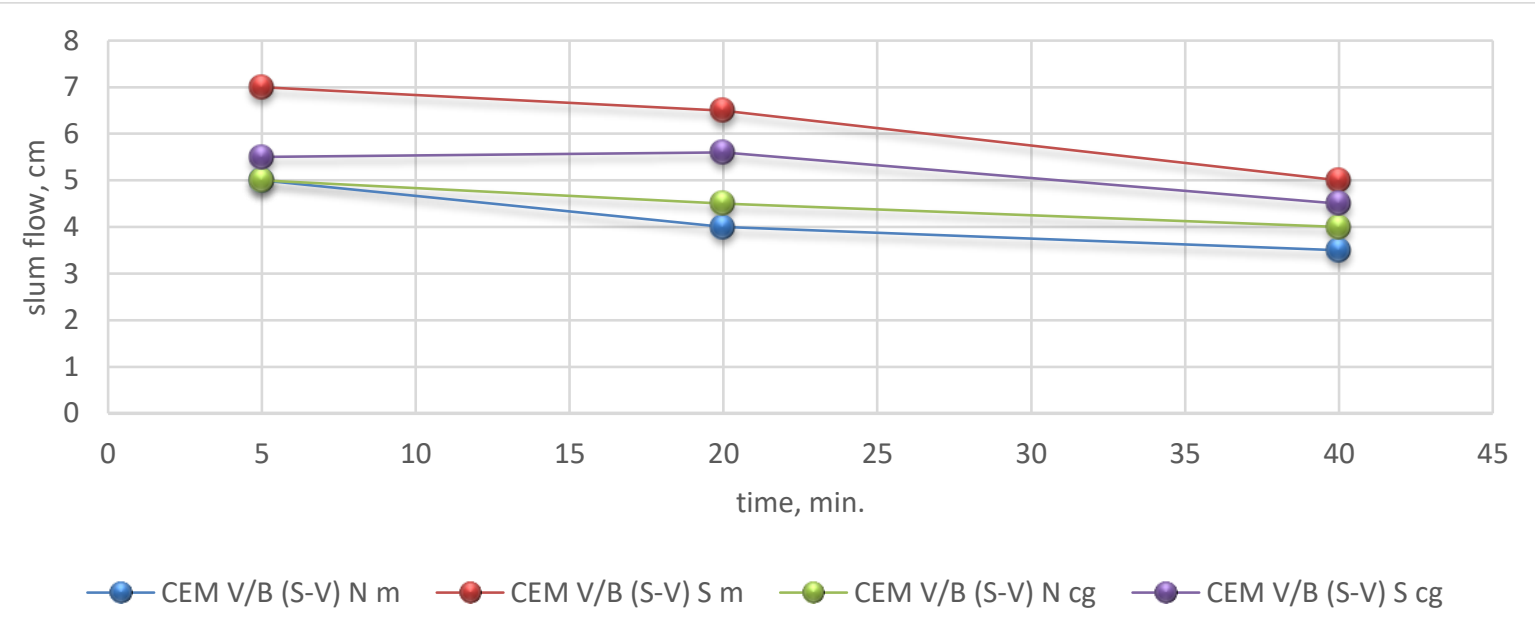

Fig. 25. Consistency of fresh concrete with CEM V/B (S-V) after 5, 20 and 40 minutes.

In order to investigate to influence of cement on air loss with time, a series of mixes were made (Table 1) with different cement type. These clearly showed the influence of cement type in depressing the air. In addition, analysis of the form of graphical relationships, replaced many times, always revealed the same characteristic form, especially at higher air content. The form of the relationships, shown in Figures 13-26, may be seen to comprise three interconnecting phases.

These can be considered as propagation, the initial loss which is rapid at first and then lessens and final loss, the period at which the rate of loss increases, markedly so if considered as a function of initial air content.t This last phase is particularly noticeable at high air contents, less so or perhaps even absent at low air contents. Both the time to reach a maximum, i.e. the length of the propagation phase and the total air gained increased with an increase in cement content. Indeed, at low cement contents, there was of course air loss and not air gain. It is b believed that these phenomena are caused by the adsorption of AEA on to the cement. This adsorption appears preferential, in that the AEA reacts first with the cement such that it does not entrain air. It then appears to progressively desorb and begin to entrain air. The reason behind this phenomenon and its reversal is unclear [26]. 
Figures from 26-31 show the porosity research results of hardened concrete including natural or synthetic air-entraining admixture. Air entrainment of fresh concrete is more or less stable, depending on the type of air-entraining admixture. In the case of synthetic admixture participation of these pores is by far the largest. However, in case of synthetic admixture, the volume of micropores with diameters less than 300 microns pore and specific surface of pores are bigger than in case natural admixture in case of N2 and S2 series, although in case of a natural admixture higher total air content was measured. This relates to the fact that the pore spacing is smaller in case of concrete made with the use of synthetic air-entraining admixture $\mathrm{S} 2$ than in case of natural $\mathrm{N} 2$ use, again, despite the fact that in case of natural admixture there is a higher total air content.

The relationship between the air-content of plastic concrete and hardened concrete is described differently in the literature. A combined field and laboratory testing program were conducted to compare air content in plastic and hardened concrete and to study the relationship of air content to vibration and compressive strength [12]. There is essentially no change in the entrained air content between plastic and hardened concrete. The results [13] show that, at the ranges commonly used in the construction of pavements and bridges, the air content of fresh concrete measured by pressure meters and that determined by the microscopical method for essentially the same concrete after hardening are, for practical purposes, the same. The air content obtained by a volumetric meter is normally run in the field is generally lower than that obtained for the same hardened concrete by the microscopical method. Whereas, research results [14] indicated that that the air content in the fresh concrete can be 0.5 to $1.5 \%$ greater than that present in the hardened concrete. The results of the tests presented in Figure 10 show that the difference between the air content in the plastic mix and hardened concrete is up to about $1 \%$, both up and down.

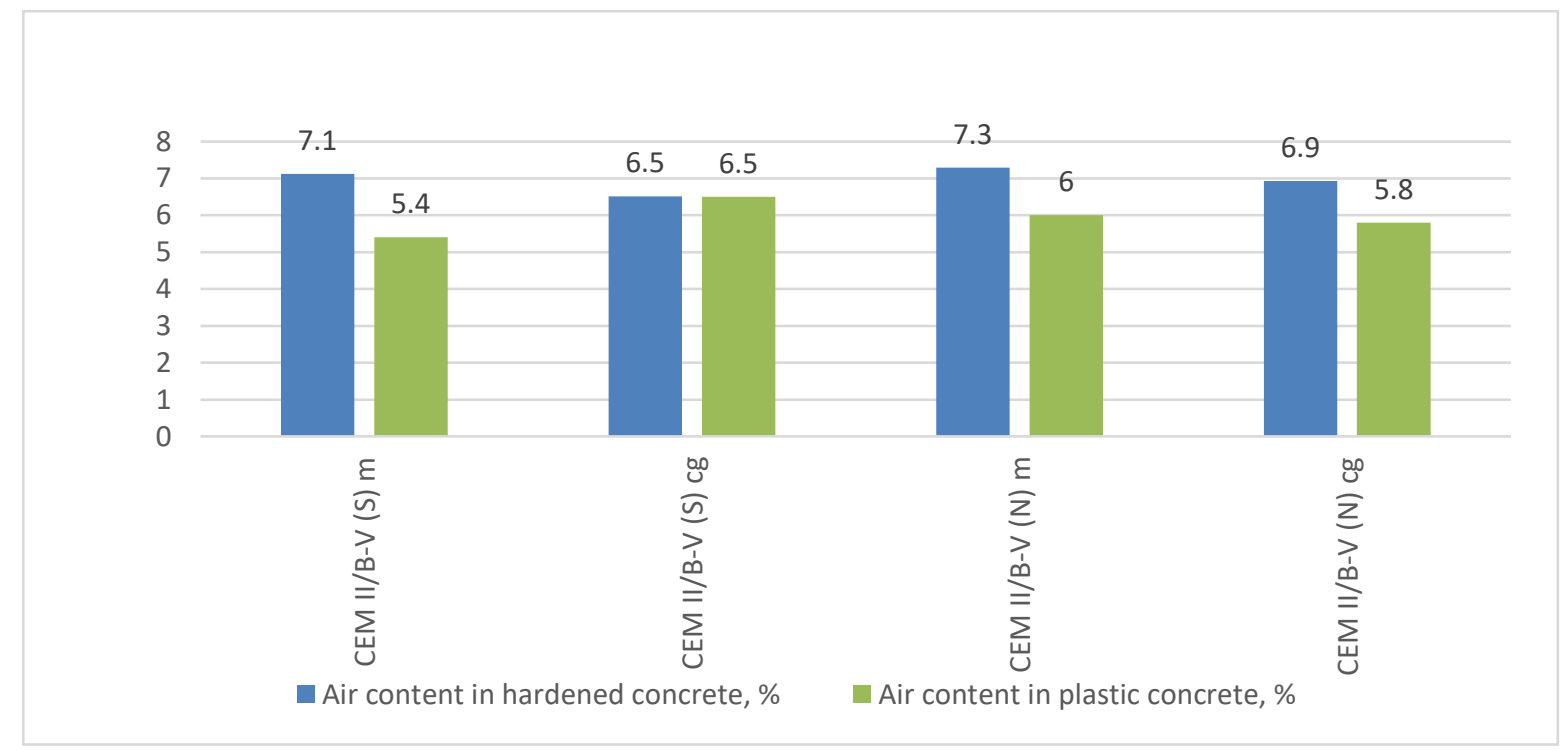

Fig. 26. The comparison between air-content in fresh and hardened concrete with CEM II/B-V 


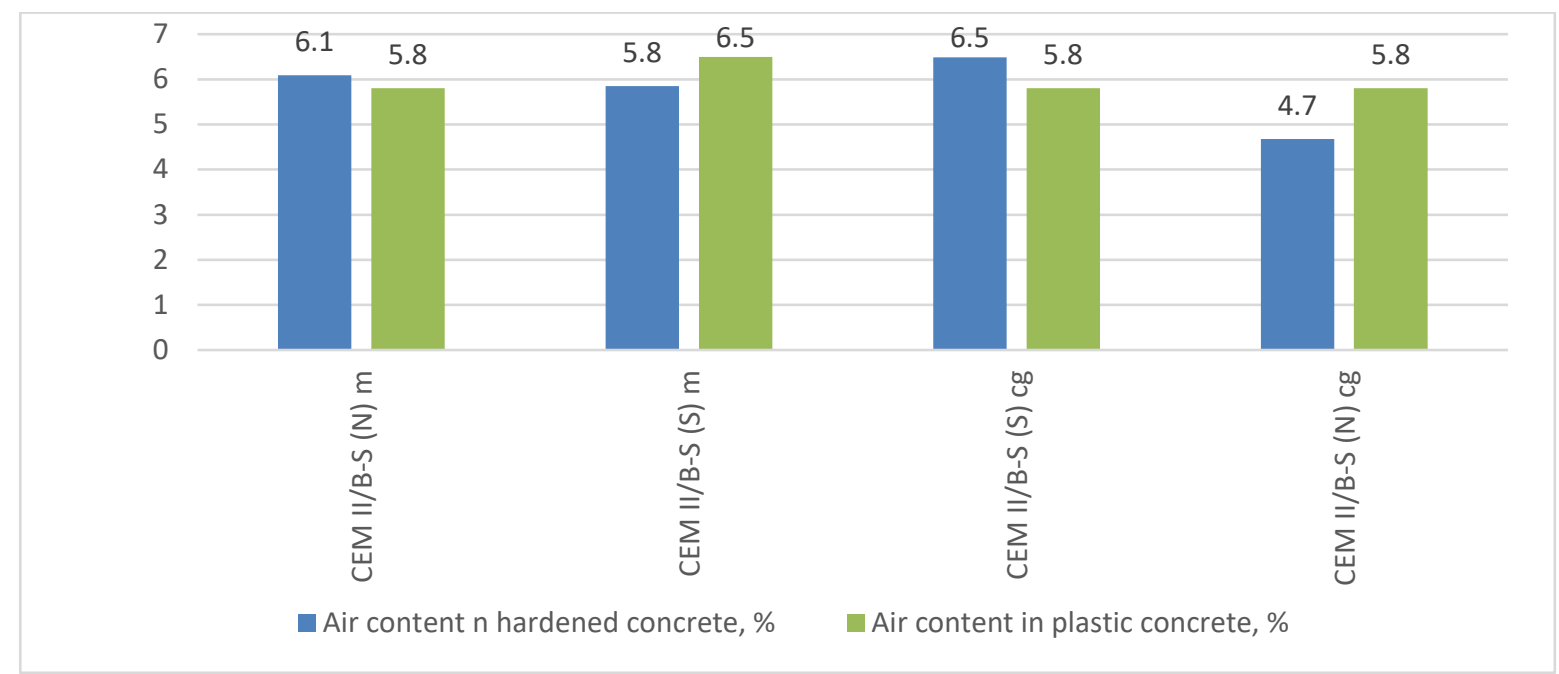

Fig. 27. The comparison between air-content in fresh and hardened concrete with CEM II/B-S

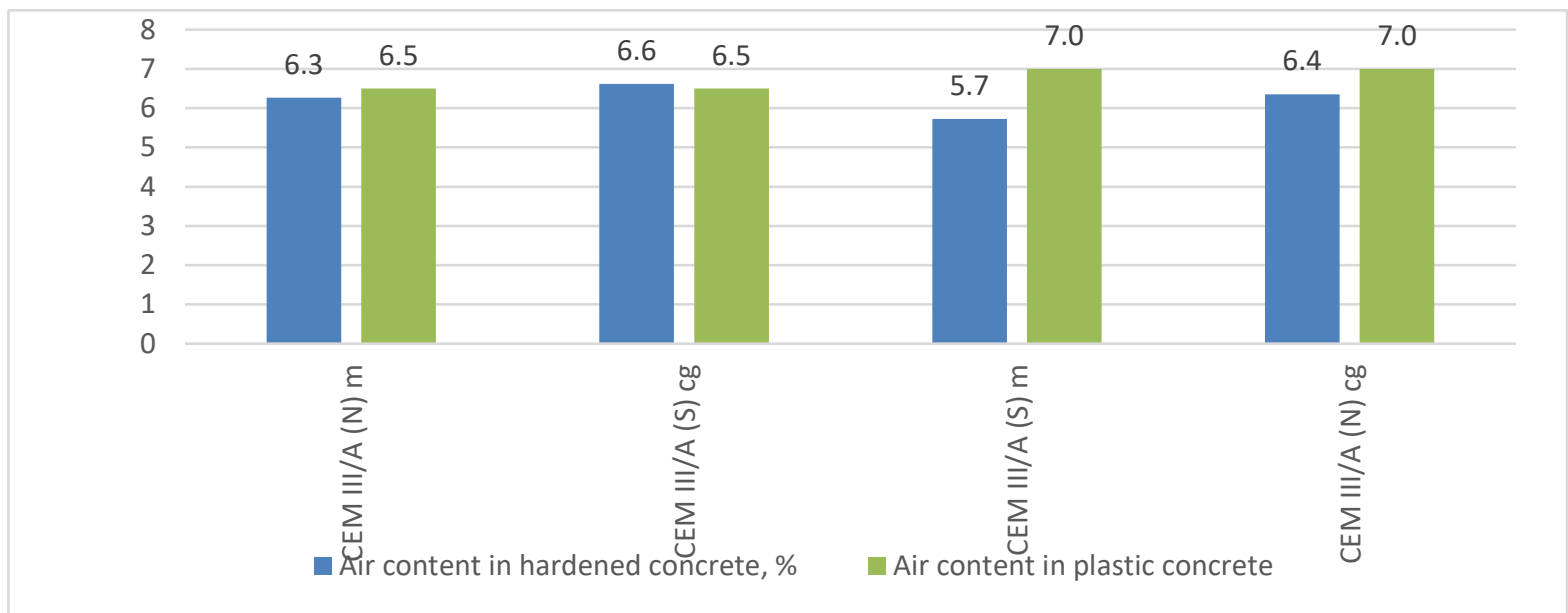

Fig. 28. The comparison between air-content in fresh and hardened concrete with CEM III/A

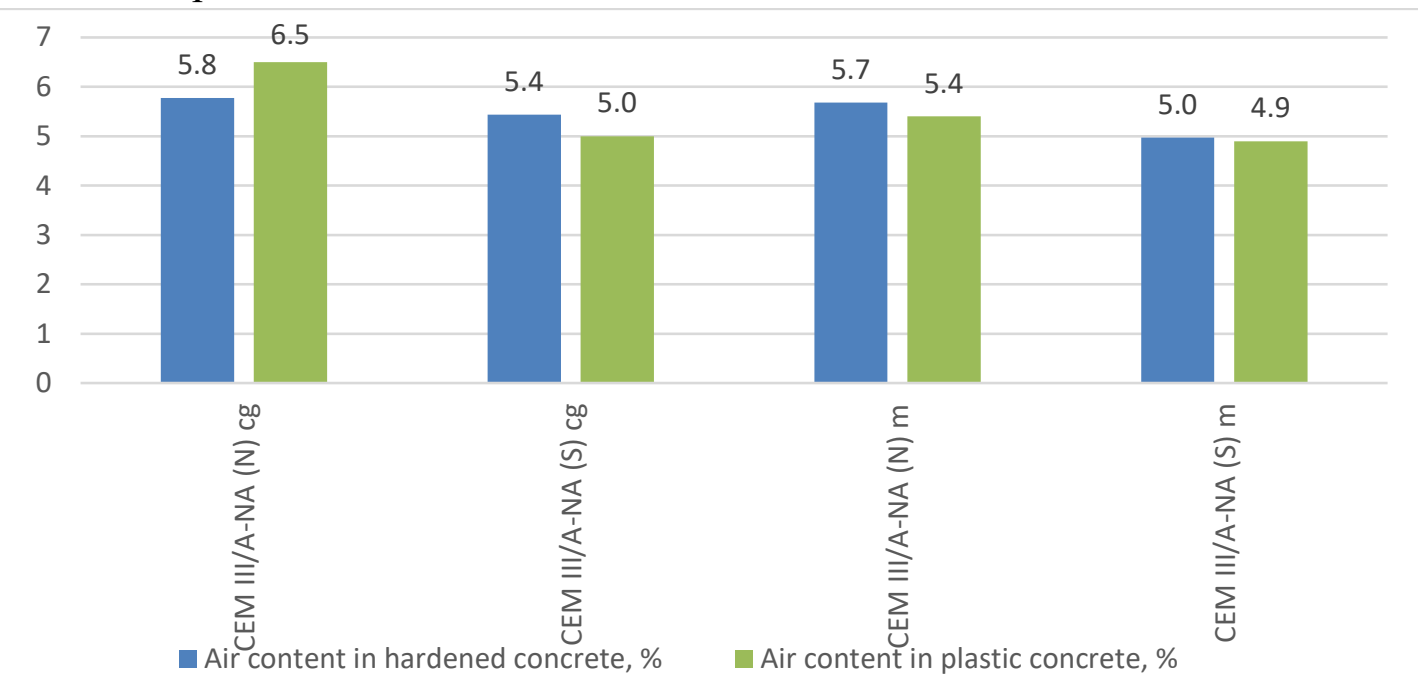

Fig. 29. The comparison between air-content in fresh and hardened concrete with CEM III/ANA 


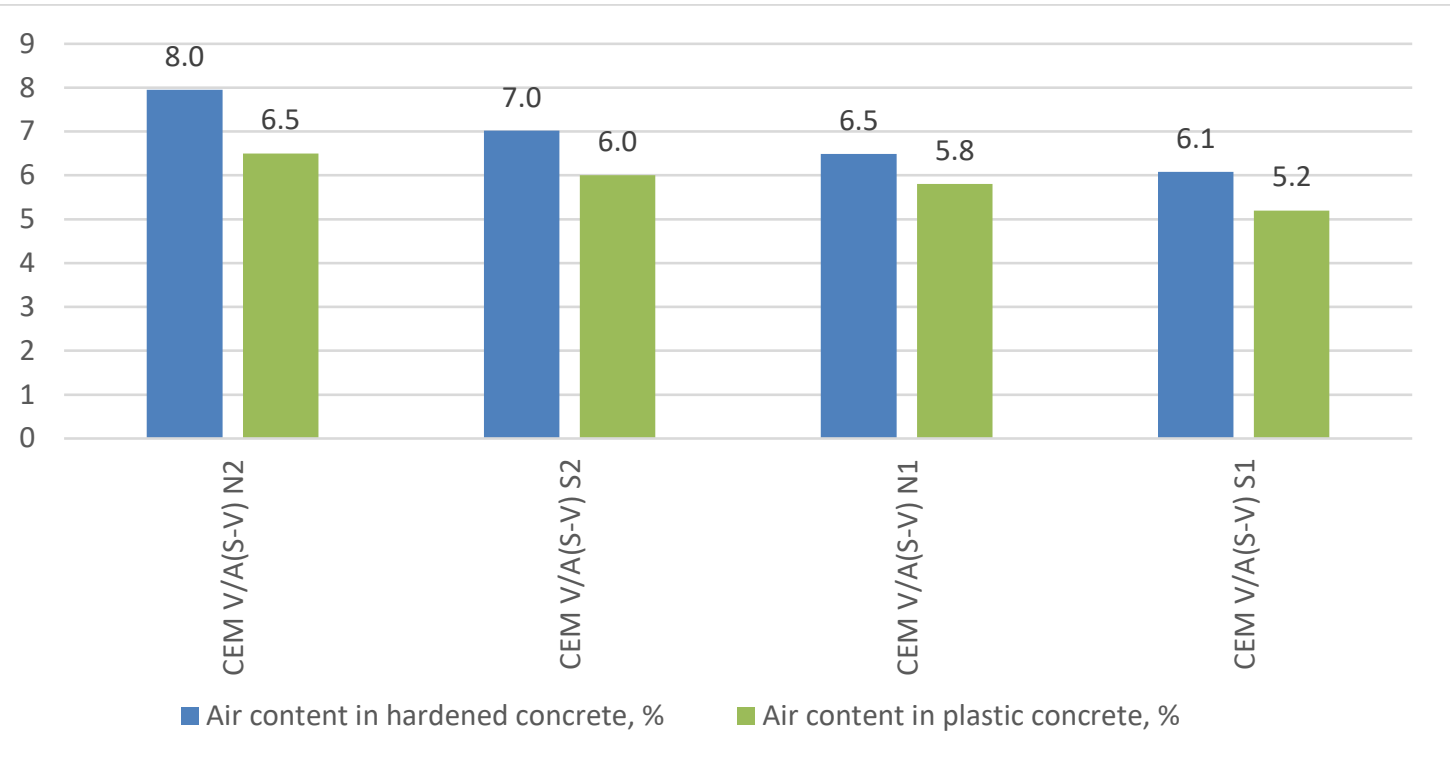

Fig. 30. The comparison between air-content in fresh and hardened concrete with CEM V/A $(\mathrm{S}-\mathrm{V})$

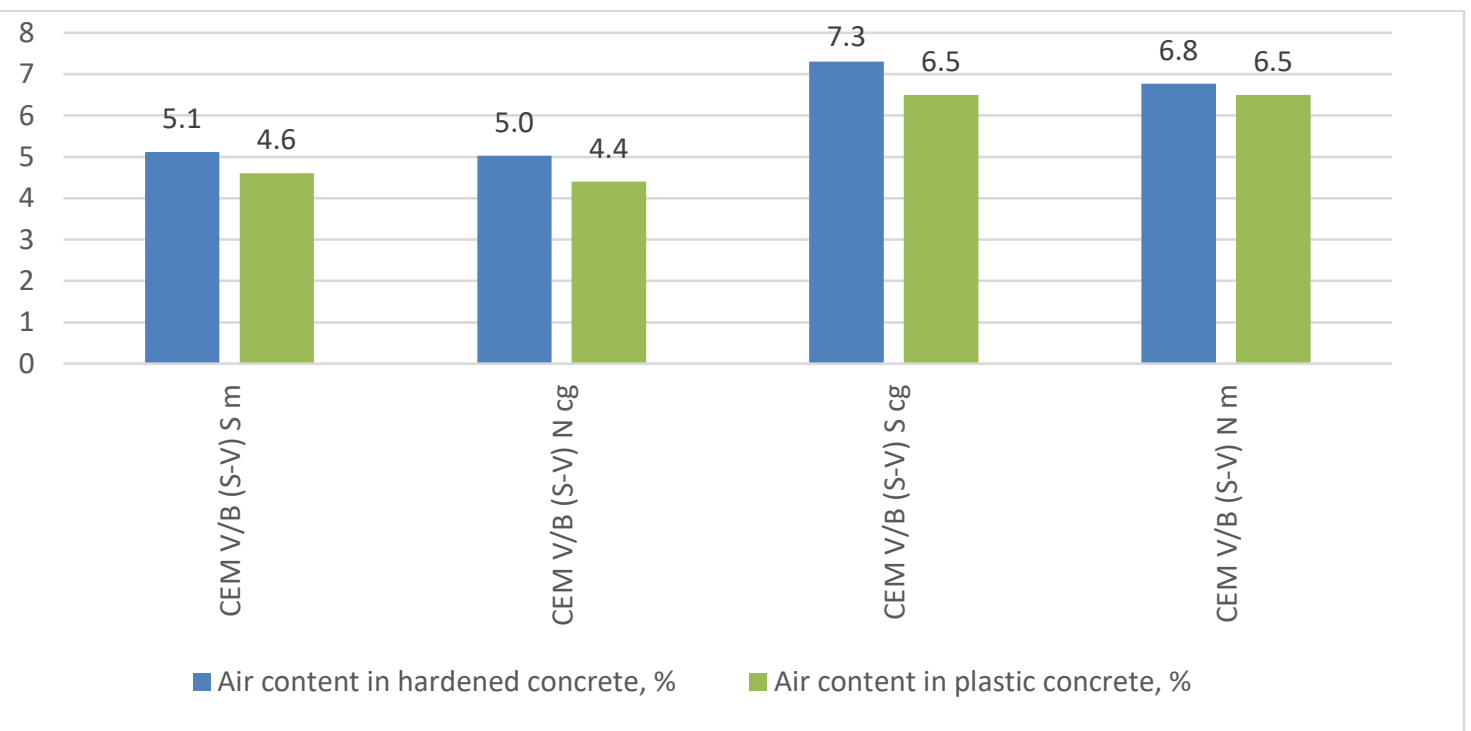

Fig. 31. The comparison between air-content in fresh and hardened concrete with CEM V/B $(\mathrm{S}-\mathrm{V})$

\section{Research Significance}

The present study reports the air content results of mixtures with different cement type and their mortar phases and demonstrates a simple technique to estimate the AEA dosage for the target air content in concrete based on air-content of modified mortar measurement (Tabe 4). The technique presented in this study will minimize the volume of experimental work to determine the AEA dosage for concrete. It will be cost-effective due to the minimum number of concrete trial mixtures, thus reducing the loss of materials and labour. 


\section{Conclusions}

Based on the research results conducted by the reference mortar and concrete according to PN-EN-480-1 (both made of the same cement type, w/c ratio and the same temperature) it is concluded that:

- There is a strong correlation between the air content in the mortar acc. EN 480-1 and plastic concrete mix acc. EN 480-1. The air content in the mortar corresponds to about half of the air content in the concrete mix. The specific volume of aggregate is an important factor for achieving adequate air-volume in the concrete mix. For smaller grains, air-content in concrete is higher than in case of bigger grains with the same mass in concrete.

- The air-content in plastic concrete good correlate with the air-content in hardened concrete determined by the microscopical method.

- To predict air-content in concrete modified mortar should be used, with double paste volume than acc. EN 480-1. The air content in concrete correlates strongly with air-content in modified mortar.

\section{Acknowledgement}

The present study was funded by the National Centre for Research and Development Project PBS1/A2/4/2012 "Innovative Cement Concrete Aerating”.

\section{Conflicts of Interest}

The authors declare no conflict of interest.

\section{References}

[1] Safiuddin, Md. et al. Air-void Stability in Fresh Self-consolidating Concretes Incorporating Rice Husk Ash" Advances in Engineering Structures, Mechanics \& Construction. Springer Netherlands, pp. 129-138, 2006.

[2] Kqlaots, I. Hurt. R.H. Suuberg E.M., Size distribution of unburned carbon in coal fly ash "and its implications" Fuel 83, vol. 1, pp. 223-230, 2004.

[3] Du L., Folliard K.J. Mechanisms of Air Entrainment in Concrete" Cement and Concrete Research, vol. 35, no. 8, pp. 1463-1471, 2005.

[4] Piasta W., Marczewska J. The effect of air entraining admixtures and cement types on the properties of fresh mortar, Structure and Environment, 2013 | Vol. 5, no. 1, pp. 11-17.

[5] Ley M.Tyler, Ryan ChanceyMaria C.G. JuengerKevin J. FolliardKevin J. Folliard The physical and chemical characteristics of the shell of air-entrained bubbles in cement paste, May 2009 Cement and Concrete Research 39(5):417-425

[6] Zhichao LiuWill HansenWill HansenBo MengBo Meng Characterisation of air-void systems in concrete, May 2015Magazine of Concrete Research 68(4)

[7] Fagerlund G.. Frost resistance of high performance concrete - some theoretical considerations" Proceedings of the RILEM International Workshop "Durability of High Performance Concrete" 14-15 Feburary, Vienna, 1994.

[8] Fagerlund G. Durability of concrete structures” Arkady, Warsaw 1999 [in Polish]. 
[9] PN-EN 480-1:2014 - Admixtures for concrete, mortar and grout. Test methods. Reference concrete and reference mortar for testing.

[10] PN-EN 1015-3:1999 Methods of test for mortar for masonry. Determination of consistence of fresh mortar (by flow table).

[11] PN-EN 1015-7:1999 - Methods of testing for mortar for masonry. Determination of air content of fresh mortar.

[12] PN-EN 12350-7:2009 Testing fresh concrete. Air content. Pressure methods.

[13] PN-EN 12350-2:2009 - Testing fresh concrete. Slump-test.

[14] PN-EN 480-11:2005 Admixtures for concrete, mortar and grout. Test methods. Determination of air void characteristics in hardened concrete.

[15] Safiuddin, M., West, J., Soudki, K. Air content of self-consolidating concrete and its mortar phase including rice husk ash / Oro kiekis savitankiame betone ir jo skiedinio dalyje su ryžių lukštų pelenais. Journal of Civil Engineering and Management, 17(3), 2011. 319-329. https://doi.org/10.3846/13923730.2011.589225

[16] Jin, J.; Domone, P. L. Relationships between the fresh properties of SCC and its mortar component, in Proc. Of the 1st North American Conference on the Design and Use of Self-consolidating Concrete, Illinois, USA, 12-13 November 2002. USA: Hanley-Wood, LLC, 2002, 37-42.

[17] Ozyildirim C. "Comparison of the Air Contents of Freshly Mixed and Hardened Concretes" Cement, Concrete and Aggregates, vol. 13, no. 1, pp. 11-17, 1991.

[18] Khayat, K.H. Nasser K.W. Comparison of Air Contents in Fresh and Hardened Concretes Using Different Airmeters," Cement, Concrete, and Aggregates vol. 13, no. 1, pp. 16-17, Summer 1991.

[19] Reidenouer, D.R. Howe R.H. Air content of plastic and hardened concrete" National Technical Information Service, Report/Paper Numbers: PDT-73-1 Final Rpt. p.73, 19752.

[20] Zhang, Z. Vitillo, M.N. Maher, A. Szary, M.P. Ansari F. Effects of Synthetic Air Entraining Agents on Compressive Strength of Portland Cement Concrete" Mechanism of Interaction and Remediation Strategy, 2002.

[21] D. S. Zhang. "Air entrainment in fresh concrete with PFA" Cement Concrete. Composites vol. 18 no. 6, pp. 409-416, 1996.

[22] D.A. Whiting, M.A. Nagi, A. Mohamad "Manual on Control of Air Content in Concrete" EB116, National Ready Mixed Concrete Association and Portland Cement Association, 42 pp., (1998).

[23] Zarauskas L., Skripkiūnas G., Girskas G.. Influence of Aggregate Granulometry on Air Content in Concrete Mixture and Freezing - Thawing Resistance of Concrete, Procedia Engineering, Volume 172, 2017, Pages 1278-1285.

[24] Zhang, S., Wang, K. Effects of Materials and Mixing Procedures on Air Void Characteristics of Fresh Concrete, Conference Proceedings, 2005.

[25] Yang QI. Stability of air bubbles in fresh concrete Master of Science Thesis in the Master's Programme Structural Engineering and Building Performance Design, 2012.

[26] Beningfield N, The air entrainment of mortar- a bibliography", 8th International Brick and Block Masonry Conference, Dublin, 1988, pp. 131-138. 